\title{
Construir en el lugar. Juan Antonio Molina Serrano: hacia el paisaje, la ciudad y el habitar
}

Juan Moreno Ortolano' | Andrés Martínez Medina ${ }^{2}$

Recibido: 08-11-2020 | en su versión final: 05-04-2021

Resumen Resistirse y renunciar: una asignatura pendiente en arquitectura, aún hoy. Más allá del universo autorreferencial que determinados ángulos interpretativos de la arquitectura actual ocupan, se dan otras visiones, más sensibles, que amplían los límites disciplinares y fracturan los discursos hegemónicos; son alternativas, miradas que interpelan a la realidad como dimensión social y que son conscientes de la importancia que el contexto, en toda su amplitud, tiene a la hora de proyectar. Las líneas que siguen resumen algunos titulares inéditos en torno a la obra del arquitecto Juan Antonio Molina Serrano. Con ellos se pretende verificar, a través del estudio de su actividad profesional, la asertividad y atención del autor hacia el paisaje, la ciudad y el espacio público. Tres ejes centrales se analizan con dicho objetivo: las intervenciones en el paisaje, puntuando escalas colectivas, domésticas y de servicio o infraestructura; las incursiones en la ciudad, distinguiendo encuentros y filiaciones con las preexistencias y la memoria urbana; y las propuestas e iniciativas en las calles y plazas, que terminan por constituir lugares recuperados y de celebración comunitaria. Todas, resumen un ideario ético y proyectual. Partiendo de una metodología que tiene como marco principal el exhaustivo estudio de los proyectos (memorias, archivo, entrevistas al autor, fuentes, etc.) y la experimentación o acción directa (habitar los edificios y casos de estudio), se pretende demostrar cómo el trabajo de Juan Antonio Molina se despliega e identifica, por encima de todo, con una postura: la escucha del lugar, el respeto por el genius loci.

Palabras clave: Construir en el lugar; ciudad; genius loci; Juan Antonio Molina

Citación

Moreno Ortolano, J. y Martínez Medina, A. (2021). Construir en el lugar. Juan Antonio Molina Serrano: hacia el paisaje, la ciudad y el habitar. ACE: Architecture, City and Environment, 16(46), 9756. DOI: http://dx.doi.org/10.5821/ace.16.46.9756

\section{To Build in a Place. Juan Antonio Molina Serrano: Towards Landscape, City and Dwelling}

Abstract

\begin{abstract}
The notions of resistance and renouncing constitute a pending issue in architecture, even today Beyond the self-referential universe that certain interpretive angles of current architectural theory occupy, there are also other sensitive perspectives that cross the disciplinary limits and fracture the normally hegemonic discourses. There are new options in the field, proposing a new gaze that challenges reality as a social dimension and is aware of the importance of context, in all its dimensions, in the development of a project. The following lines synthesize some unprecedented reflections on the work of the Spanish architect Juan Antonio Molina. The purpose of this paper is to prove Molina's assertiveness and attention towards landscape design, the city and the social space created in those domains. In this line, three central axes are considered: interventions in the landscape, through the analysis of collective, domestic and service or infrastructure scales; forays into the city, through the discussion of his encounters and affiliations with pre-existing spaces and the urban memory; and his proposals and initiatives related to the public space, which, ultimately, have become recovered spaces and places for social celebration (Pallasmaa, 2016). All of them, together, function as a resonance box for the inclusion of an ethical statement of principles. Combining a methodology focused on the exhaustive study of Molina's projects (through memories, archives, interviews with the author, sources, etc.), together with experimentation and/or direct action (inhabiting buildings and case studies), my aim is to demonstrate the ways in which Molina's work has evolved into and is related to, above all, a specific position: that of listening to the place, with the respect for the Genius Loci.
\end{abstract}

Keywords: To build in a place; city; genius loci; Juan Antonio Molina

${ }^{1}$ Licenciado y Máster en Historia del Arte, Docente Carrera de Arquitectura UNLaM. Buenos Aires (ORCiD: 0000-0001-6372-8259, Researcher ID: AAN-3345-2021), ${ }^{2}$ Dr. Arquitecto. Profesor Titular, Universidad de Alicante (ORCiD: 0000-0002-5309-9310, Scopus Author ID: 56024428600, Researcher ID: C-4296-2015). Correo de contacto: jmoreno@unlam.edu.ar, andresm.medina@ua.es 


\section{Génesis y ejes centrales para una arquitectura del lugar}

"Es en el lugar, donde el edificio adquiere la necesaria dimensión de su condición única, irrepetible; donde la especificidad de la arquitectura se hace visible y puede ser comprendida, presentada, como su más valioso atributo" (Moneo, 1995).

Juan Antonio Molina Serrano (1944) inicia su trayectoria a finales de los años sesenta. Nacido en Murcia, en el levante mediterráneo español, realiza sus estudios en la Escuela Técnica Superior de Arquitectura de Madrid entre los años 1962 y 1969, bajo el magisterio de personajes tan destacados, en aquellos momentos, como Javier Carvajal o Juan Daniel Fullaondo. En esos mismos años, crea su propio estudio. El definitivo reconocimiento de la labor profesional de Juan Antonio Molina Serrano, que las numerosas distinciones recibidas o proyectos premiados corroboran, se afianza con la reciente aparición del libro dedicado a toda su trayectoria profesional (VV.AA., 2019). Asimismo, su trabajo ha sido catalogado e incluido recientemente en el Registro DOCOMOMO Ibérico; un buen ejemplo del mismo sería el Colegio Santa María del Carmen, que el autor realizó en 1973-75 con la colaboración de Vicente Pérez Albacete y Mariano Ruipérez Abizanda.

Gran parte de su actividad profesional se reparte por la zona del sureste de España y en ella se manifiesta, ya desde muy temprano, una actitud que va a estar presente en todo su trabajo como arquitecto: la escucha sensible del lugar (Thornberg, 1973; De Las Ribas, 1992), su genius loci (NorbergSchulz, 1979)1. Esta cuestión, que constituiría -como bien sabemos- el origen de un debate importante en la España del último tercio del siglo XX, impregna toda la acción de proyecto del arquitecto murciano. $Y$ es desde la lectura atenta y comprometida con dicha polémica desde donde puede sostenerse un discurso que, en su naturaleza, encierra la heterogeneidad del legado arquitectónico de este profesional. Su trabajo, de esta manera, implicará en su génesis un marco de resistencia, una renuncia disciplinar: el abandono de la condición objetual de la arquitectura y de sus añadidas tentaciones. Supondrá también, y por la misma razón, un entender la arquitectura como un campo de acción profesional irremisiblemente unido a la sociedad y al lugar en donde se proyecta y que, por consiguiente, no puede abastecerse únicamente de sus posturas internas hegemónicas ni claudicar ante los referentes y signos del habitar exteriores, sino que, abiertamente, debe apelar al reflexivo empleo de las diferentes temáticas que conviven con la propia disciplina; coordenada de partida que Luis Eduardo Bresciani -dentro de un contexto de pensamiento semejante- mantiene: "Sólo cabe resistirse a la idea de que ampliar el debate arquitectónico a los grandes temas de nuestro tiempo nos podría distanciar del oficio del proyecto. Por el contrario, la necesidad de permanente ajuste y sintonía con los nuevos contextos globales obliga a tensionar y someter a crítica permanente lo que hacemos" (Bresciani, 2020, p. 153). En la producción de Juan Antonio Molina no encontraremos una coherencia al uso ni tampoco la pertinente búsqueda de un ideal compositivo o formal, sino, más bien, el resultado de un compendio de experiencias que se ven matizadas y encuentran su camino definitivo, precisamente, en las distintas e intransferibles características que cada lugar pudo ir ofreciendo en el tránsito de su aventura proyectual. Desde ahí se construye su propuesta, en un viaje de ida y vuelta que hará presentes, tanto al inicio como al final, las mismas interrogantes, alternativas y problemáticas.

Desde una aportación o investigación inédita se proponen tres ejes que pueden identificarse, con sus matices, como temas comunes de su trabajo: las incursiones que se despliegan en el 'paisaje', las que se dan en la 'ciudad' o el espacio urbano y, por último, aquellas que dirigen su atención hacia los espacios de relación y comunidad social. El primero de los acercamientos muestra la particular

\footnotetext{
1 “La idea de «genius loci» se basa en la antigua creencia romana de que todo ser independiente tiene su «genius» o espíritu guardián. Los dioses familiares que habitaban la casa romana eran los lares -espíritus guardianes de la casa-, los genius -divinidades tutelares del cabeza de familia- y los penates -divinidades protectoras de la comida-" (Montaner, 1994, p. 11).
}

ACE, 16 (4.6) CC BY-ND 3.0 ES | UPC Barcelona, España | Construir en el lugar. Juan Antonio Molina Serrano:

hacia el paisaje, la ciudad y el habitar. DOI: http://dx.doi.org/10.5821/ace.16.46.9756 
manera del arquitecto de atender al paisaje y la topografía, combinando proyectos que se mueven entre lecturas construidas en la excavación del terreno con aquellos que quedan imbricados orgánicamente en su contexto. Otros, sin embargo, cristalizarán en hitos en el paisaje; hitos que irán matizando los distintos contextos en los que se implantan. En ambos posicionamientos se incluirán muy distintas soluciones, que oscilan entre el Transformador (1972-73), pasando por el proyecto no realizado del Centro de Ocio en Altorreal (1985), la Casa Serrano (1994), el Conjunto de Viviendas en Guardamar (1995) o la icónica actuación en el Pozo de Bombeo (1998-2000), en la huerta murciana. En los lugares urbanos se fluctúa entre una serie de intervenciones que activan una amable discusión con las preexistencias históricas y aquellas que terminarán convirtiéndose en imprescindibles para entender la nueva imagen a la que aspira la ciudad. En el primer grupo tienen cabida los Edificios del Romea (1973-77) y Arco de Santo Domingo (1976-80), y -con posterioridad- la que puede considerarse como una de sus actuaciones que define su poética más personal: el Centro de Artesanía de Lorca (1985-88). El segundo grupo tendrá en los Edificios realizados para la Empresa Alimentaria HERO (1985-2006) y el Centro de Artesanía de Murcia (1989-92) sus más claros exponentes. Un caso especial lo constituirá el Edificio Anexo para la Facultad de Derecho (2008-12), que cierra su trayectoria profesional y entra a formar parte de una familia de proyectos construidos: Escuela de Biblioteconomía y Ciencias de la Documentación (1996-2000), Facultad de Psicología (2000-07) y Archivo Provincial Histórico de Murcia (2000-04), realizados conjuntamente con los arquitectos José Luis de Arana y María Aroca.

La construcción del lugar social y los espacios para el habitar serán, para Molina, un desafío constante que atravesará prácticamente toda su carrera profesional y que, por ello, estará presente en muchos de sus encargos. La arquitectura pasará a ser entendida, así, como un motor que impulsa y fortalece los lazos de unión, relación y comunicación social (Gehl, 2006). Esta será, pues, la principal fuente de su trabajo como arquitecto (Moreno, 2017; Moreno, 2018), al constituir una característica inherente al mismo, reunida con mayor o menor intensidad en gran parte de su producción. Aquí estarán presentes, no solo las intervenciones en espacio público, como el proyecto para la Plaza de Santo Domingo (1988) -no realizado- y su heredera directa, la Plaza de Santa Isabel (1998-2000), sino también el Colegio Santa María del Carmen (1973-75) y otros, que van desde la escala más pública hasta la más íntima o doméstica, como el grupo de viviendas en Guardamar, el Edificio Infantes o la Casa Serrano

\section{Hacia el paisaje}

El Transformador para el ceramista Pedro Borja (1972-73) explica, desde muy temprano, las intenciones discursivas de Molina de cara al contexto y el paisaje (Figuras 1, 2 y 3). Este trabajo, que enlazará directamente con el posterior para el Centro de Artesanía de Lorca, nace de una decisión inicial de proyecto: soterrar el edificio. No solo son las razones programáticas las que conducen a la solución de albergarlo bajo tierra, sino también la de cuidar el entorno en donde se sitúa. Se trata de un edificio 'excavado' en la tierra, que genera un prisma de hormigón rectangular desde el cual emerge la torre, de 9 metros de altura -ladrillo 'gafas', por la exposición directa de los orificios que lo permean a lo largo de la pieza, dejado a cara vista-, que se eleva con el fin de recoger los cables de energía eléctrica y trasladar esta al horno interior. Dos pueden considerarse las premisas fundamentales del proyecto: facilitar un encuentro amable con el terreno, respetando la línea natural o barrera blanda determinada por los limoneros colindantes, y trabajar desde un lenguaje compositivo y material deliberadamente expresivo, pero sujeto a una paleta muy reducida de materiales: hormigón visto en los muros portantes y ladrillo cerámico en los cerramientos. El programa básico de esta pequeña infraestructura o transformador eléctrico, implementado con la particularidad del horno para un artesano, se encaja en un basamento horizontal, de manera que se ubiquen el propio horno de cocción, el taller del artista y la sala de exposición en el nivel en contacto con la tierra y se dispongan 
las instalaciones de cableado en el hito vertical que se eleva por encima. El Transformador concilia con las aproximaciones orgánicas que durante los años cincuenta y sesenta vienen a constituir una influencia relevante en el panorama nacional e internacional: destellos de Higueras, Miró, Oíza, Carvajal o el propio Fernández Alba, resuenan en este proyecto iniciático, dando testimonio de una tal cercanía, así como de los aprendizajes adquiridos por Molina durante sus años juveniles en la Escuela de Arquitectura de Madrid.

Figuras 1, 2 y 3. Transformador para el ceramista Pedro Borja, J. A. Molina, Murcia, España

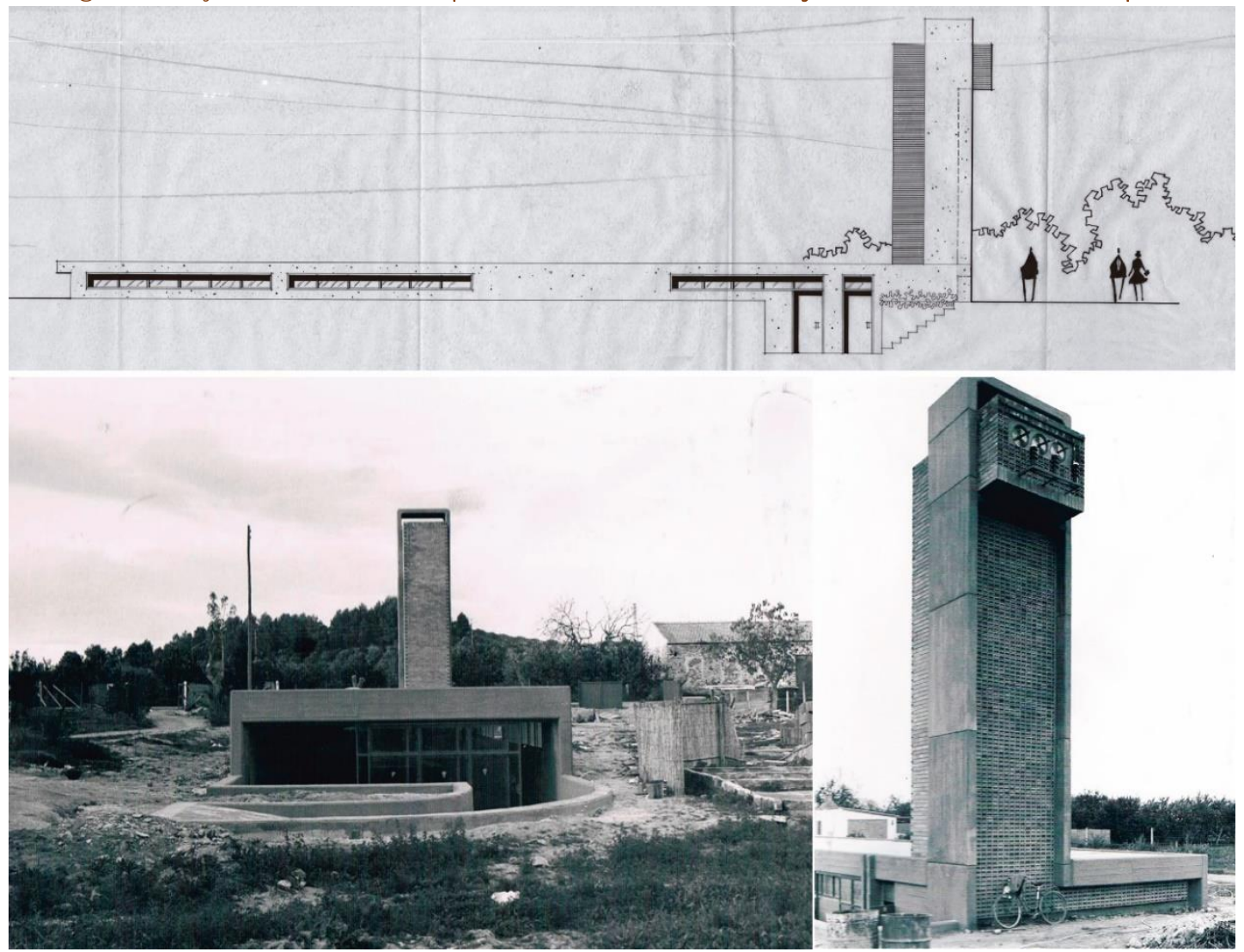

Fuente: APM y AP-jaMS.

En un punto intermedio de esta búsqueda de la arquitectura como lugar, espacio existencial, más concreto y empírico (Norberg-Schulz, 1975) aparecerá el proyecto -no realizado- para el Centro de Ocio en Altorreal (1985), que insiste, ya de manera más evidente, en una estrecha relación entre la arquitectura y el enclave natural (Figura 4). Distintos volúmenes generan un edificio alfombra o matbuilding ${ }^{2}$-estrategia compositiva ya utilizada, como veremos, en el Colegio Santa María del Carmen (1973-75; Figura 5) -, en donde se van situando pérgolas, galerías y muros que terminan por acotar e identificar distintos espacios. El edificio alfombra, organizado en torno a una malla reticular de patios interiores, se adapta a la topografía ligeramente accidentada del terreno, dando como resultado un organismo arquitectónico en el que la 'alfombra' no es horizontal, sino que replica el perfil de la orografía, dejando los espacios intermedios e interiores a diferentes niveles. El recurso del muro o de la tapia como sistema para integrar el artificio con la naturaleza circundante y auxiliar en el 'amparo' térmico o ambiental se dibuja en los croquis del arquitecto desde el pronunciado acompañamiento

\footnotetext{
2 "El mat-building se estructura en diversos tipos de recorridos -verticales, horizontales, inclinados- que se convierten en los sistemas articulatorios, ya que un tapiz está siempre hecho de nudos. En definitiva, el mat-building se caracteriza por la capacidad para crear su propio microclima, para ser como microciudades" (Montaner, 2008, pp. 98-99).
}

ACE, 16 (4.6) CC BY-ND 3.0 ES | UPC Barcelona, España | Construir en el lugar. Juan Antonio Molina Serrano:

hacia el paisaje, la ciudad y el habitar. DOI: $\underline{\text { http://dx.doi.org/10.5821/ace.16.46.9756 }}$ 


\section{ACE Architecture, City and Environment}

e-ISSN 1886-4805

de la vegetación; aspecto, este último, que subraya un interés -inicial en la trayectoria de este profesional- por las masas arbóreas y la flora abundante, que aquí diluyen o matizan la aparición y exposición del conjunto, a fin de unirlo estrechamente con su entorno. Este primer apunte intencional no construido sí podrá descollar más tarde en las viviendas en Guardamar y la Casa Serrano, lo cual anuncia su proximidad con respecto a otro maestro admirado por Molina y, por estos años, descubierto y reivindicado por la crítica: Luis Barragán.

Figura 4. Centro de Ocio en Altorreal, J. A. Molina, Murcia, España

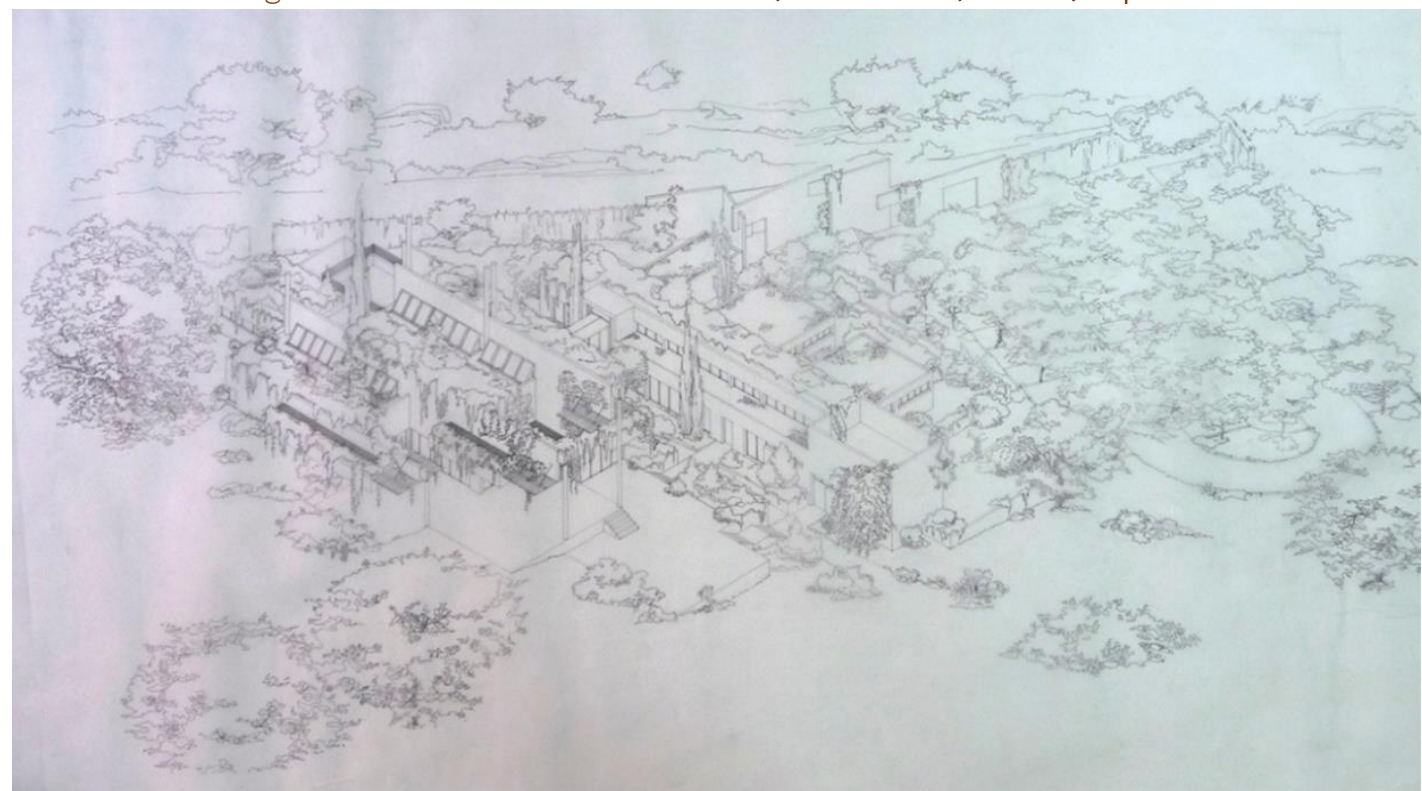

Fuente: APM y AP-jaMS.

Figura 5. Colegio Santa María del Carmen, J. A. Molina, M. Ruipérez A. y V. Pérez A., Murcia, España

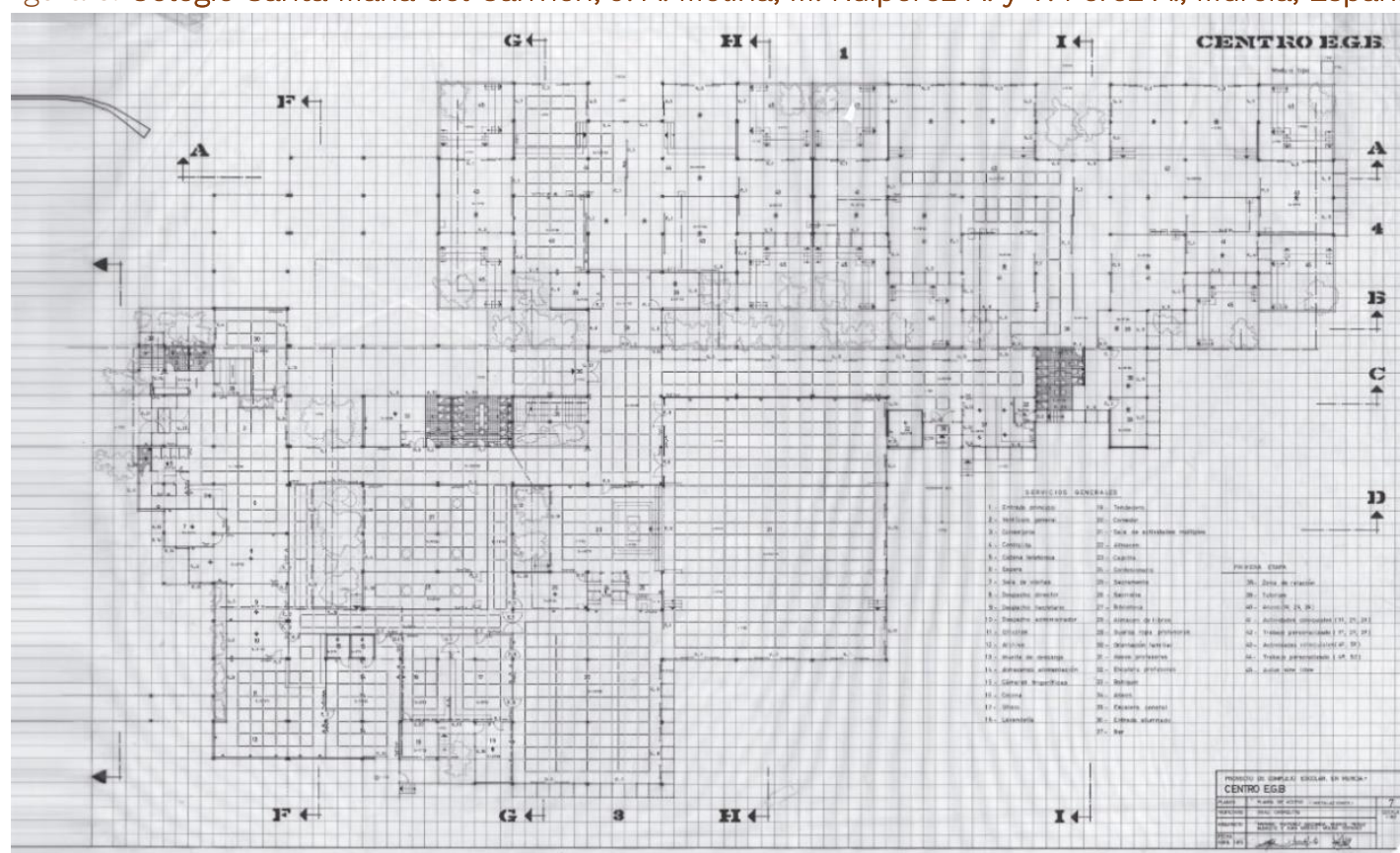

Fuente: APM y AP-jaMS.

ACE, 16 (4.6) CC BY-ND 3.0 ES | UPC Barcelona, España | Construir en el lugar. Juan Antonio Molina Serrano:

hacia el paisaje, la ciudad y el habitar. DOI: http://dx.doi.org/10.5821/ace.16.46.9756 


\section{ACE Architecture, City and Environment}

El Conjunto de Viviendas Guardamar (1995), así como la Casa Serrano (1994), concurren en posturas de talante marcadamente escénico. La Casa Serrano (Figuras 6 y 7) se organiza compositivamente en patios, terrazas y largas promenades; se pone en juego la acomodación de distintos 'estratos de la intimidad' que se van dispersando u organizando desde la entrada o acceso, "inventando particulares paraísos herederos de la tradición musulmana” (VV.AA., 2019, p. 358). El patio actúa como catalizador de las energías espaciales: favorece el contacto de las estancias con el exterior y las protege, canaliza el aire y permite controlar la cantidad de luz solar y, por ende, regular la temperatura, pudiendo incorporar elementos vegetales que ayuden a todos estos fines y hagan así más agradable y confortable su uso y disfrute como espacios vivideros casi exteriores. Puesto que uno de los requisitos de partida del programa, impulsado por las propias necesidades del cliente, consistía en relacionar las horas del trabajo y estudio con el paseo, la casa se entiende aquí como la prolongación de un recorrido 'meditado e intelectual' que se inicia en el interior de la biblioteca y termina enmarcado en el jardín, las vistas sobre el paisaje y el lejano perfil de la ciudad ${ }^{3}$. Por esta misma razón, los recorridos de los corredores de cierre y de la arquitectura que envuelve los patios -terrazas - tienden a la continuidad espacial y refuerzan la relación entre el interior y el exterior, al tiempo que subrayan la perseguida ilusión del paseo o promenade espacial.

Figuras 6 y 7. Casa Serrano, J. A. Molina, Murcia, España

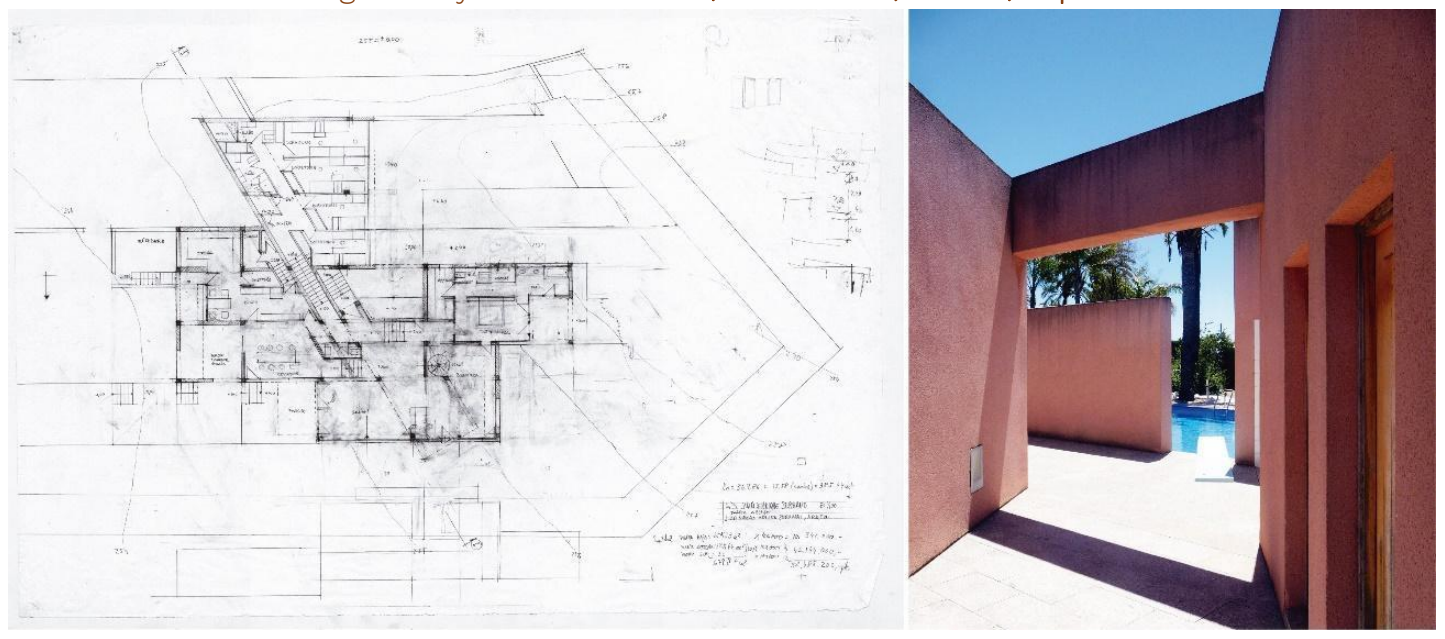

Fuente: APM y AP-jaMS.

Tanto el patio como estos recorridos derivan de una fuerte tensión que, en síntesis, resuena en toda la vivienda: confinar y recluir; expandir y extender. Sobre esta polaridad, Carlos Martí Arís (2008) comenta: "El patio se asocia a lo cóncavo e interiorizado, a la construcción de un recinto y a la apertura cenital; mientras que el pabellón se asocia a lo convexo, a la construcción de un techo, al carácter centrífugo y a la apertura visual hacia el horizonte. En su reducción más esencial, el patio se identifica con un muro que delimita un lugar, mientras que el pabellón se asimila a un techo que protege y expande la visión lateral. El patio es una estancia sin techo. Suele ser un espacio central, nuclear, al que vierten las demás habitaciones y donde se establece la relación entre todas ellas" (p. 17).

La Casa Serrano se presenta desde esa polaridad al conjugar, desde la atmósfera doméstica, los distintos caminos de apropiación que la vivienda desglosa sobre el entorno que la rodea y la parcela en donde se sitúa. Toda la casa vela los recorridos tras los muros - desde una declarada significación constructiva - y los umbrales, definidos por la vegetación, creando una sutil escenografía que culmina en el trampolín de la piscina. El programa se distribuye en dos zonas: de día y representativa -estar,

${ }^{3}$ (Moreno Ortolano, J., comunicación personal, 16 de marzo de 2015).

ACE, 16 (4.6) CC BY-ND 3.0 ES | UPC Barcelona, España | Construir en el lugar. Juan Antonio Molina Serrano: 


\section{ACE Architecture, City and Environment}

comedor, despacho y dormitorio- y de noche, más íntima y familiar -resto de dormitorios y bañosEn resumen, la vivienda participa de dos soluciones esenciales para organizar el espacio familiar: por un lado, se desahoga, respira y vive gracias a los patios, alrededor de los cuales giran las salas y estancias que se articulan con sistemas de recorridos básicos: pasillos, corredores, vestíbulos, recibidores y escaleras; y por otro, habilita otros lugares de desplazamiento, como rampas, porches, galerías y terrazas, que comunican la vivienda con su exterior, facilitando así la permeabilidad, continuidad y unidad con los espacios adyacentes y el paisaje contiguo y remoto a la casa.

En Guardamar (Figuras 8 y 9) se harán ya muy presentes determinadas gramáticas -a posteriori reconocibles iconografías del autor-, con las que Molina organiza y distribuye las distintas piezas de la urbanización. Un sistema de plataformas, pérgolas y galerías se disponen en torno y a lo largo del motivo central de los espacios comunitarios ajardinados, atravesados estos por la piscina central que ejerce de punto de gravedad del complejo. Dicho sistema fija con absoluta nitidez su aparición en un emplazamiento de leve desnivel, que viene a unificarse desde el ritmo y relación de los citados elementos de composición; de la misma manera y desde ese cosido, se organiza un entorno colectivo de relación que vuelve a involucrar afectivamente la arquitectura con la acción del habitar, con su contexto y el paisaje circundante. Con Guardamar podrá corroborarse, también, su proximidad al universo ilusorio e imaginativo del tándem Carme Pinós y Enric Miralles, así como a la tradición constructiva mediterránea, aunque aquí muy alejada de los lenguajes y soluciones de la arquitectura residencial turística que se pliega a los intereses del mercado inmobiliario.

\section{Figuras 8 y 9. Conjunto de Viviendas Guardamar, J. A. Molina, Murcia, España}

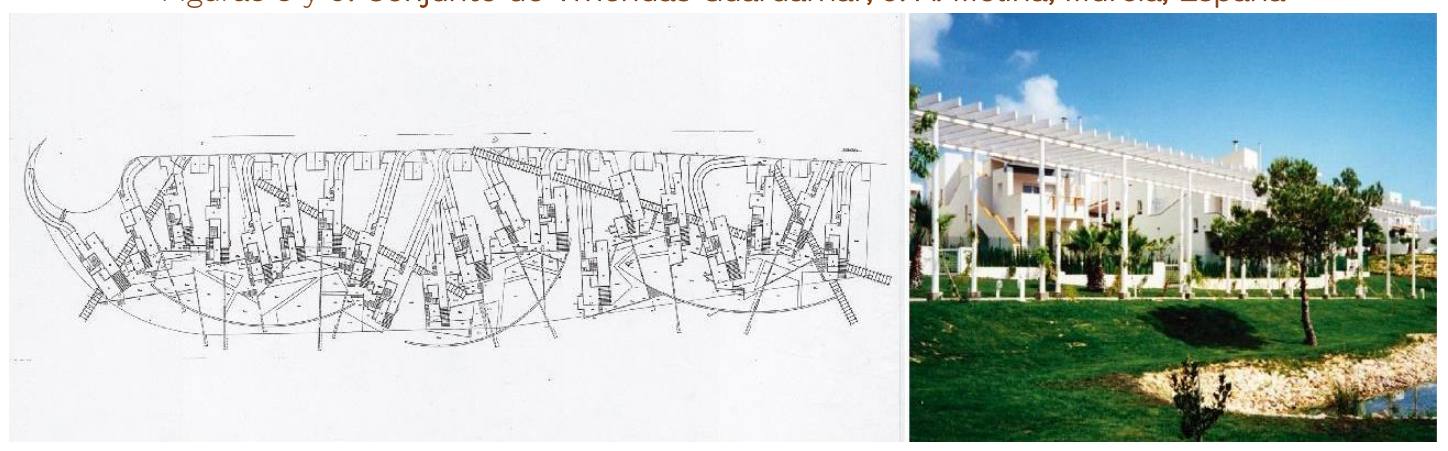

Fuente: APM y AP-jaMS.

Figuras 10 y 11. Pozo de Bombeo para Aguas Residuales, J. A. Molina, Murcia, España.

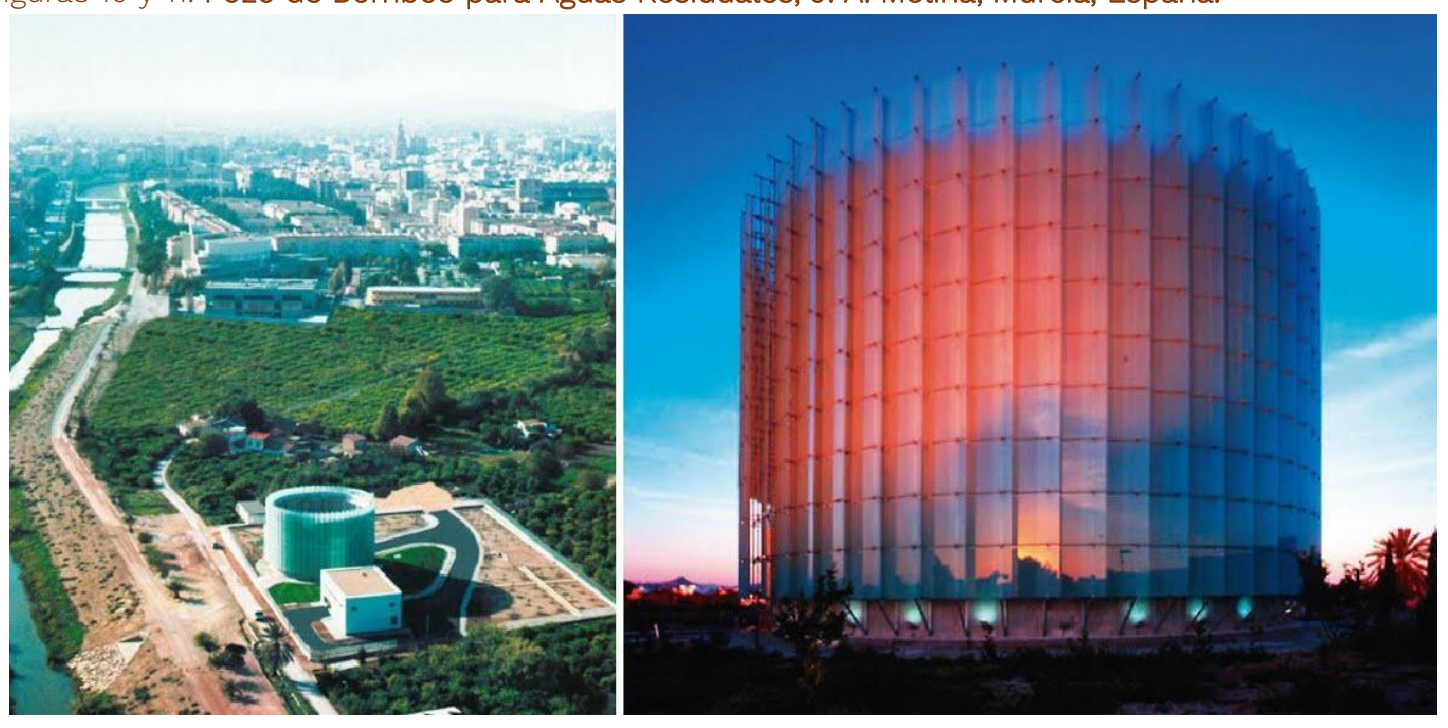

Fuente: APM y AP-jaMS.

ACE, 16 (4.6) CC BY-ND 3.0 ES | UPC Barcelona, España | Construir en el lugar. Juan Antonio Molina Serrano: hacia el paisaje, la ciudad y el habitar. DOI: http://dx.doi.org/10.5821/ace.16.46.9756 
Desde una perspectiva distinta tiene que observarse el Pozo de Bombeo para Aguas Residuales (19982000). Si en los anteriores la arquitectura juega a tener un papel matizador y fuertemente vinculado a su contexto, este último se presenta desde una línea fundamental: la neutralidad (Figuras 10 y 11). Se trata de un ejercicio basado en el empleo de una geometría elemental y rotunda en su forma y material. Se recurre a un cilindro recubierto de una piel o superficie de vidrio laminado: una pátina material traslúcida que busca exponerse en el paisaje y el entorno durante el día y que, por la noche, de manera distintiva, se transforma en un faro de luz que se identifica sobre la huerta y su extensión. De esta manera, se halla como hito en el paisaje -circunstancia parcialmente compartida en el antecedente del Transformador- a través de cierta abstracción neorracionalista, muy en boga en estos años en España y que bien podría incluirse en la "indisimulada tradición racionalista" que Antón Capitel (2002, p. 7) identifica como modo de hacer arquitectónico de la España que cierra el último decenio del siglo.

\section{Hacia la ciudad y el espacio urbano}

Dos grupos de edificios destacan en las actuaciones en las tramas urbanas llevadas a cabo por Juan Antonio Molina: Los Edificios del Romea y Arco de Santo Domingo y los Centros de Artesanía y HERO. Los Edificios del Romea (1973-77), realizados conjuntamente con Mariano Ruipérez Abizanda y Vicente Pérez Albacete, deben ser entendidos como dos fases con vocación de unidad que generan un lienzo de fachada que cierra toda una manzana de la trama densa de la ciudad histórica junto a la plaza del Teatro Romea (Figuras 12 y 13). Se trata de una propuesta sutilmente vecina a la Escuela de Barcelona y a figuras capitales de estos años, como el equipo Bohigas-Martorell-Mackay, y que, por tanto, tiene que ser entendida más como una 'coincidencia coyuntural' que como un 'propósito de estructura'; circunstancia propia de los miembros que se reúnen en torno al grupo catalán (Bohigas, 1966). Así, pues, resultan oportunos algunos temas o problemáticas sostenidos por aquellos, encontrados en los Edificios del Romea, tales como haber mantenido una postura que se desmarca de los neobarroquismos, todavía vigentes durante los años setenta en Murcia (Hervás, 1981), como al pretender canalizar cierto vanguardismo y un relativo afán tecnológico formulado desde la combinación de las técnicas contemporáneas y su costura con las tradicionales, al igual que al mostrar o estar convencido, por afinidad con determinados principios teóricos o ideas, de que la arquitectura "no es una exigencia de creación monumental, de definición de genialidades individuales, sino una simple posibilidad de servir a los intereses colectivos de una manera inmediata y muy concreta” (Bohigas, p. 26).

Figuras 12 y 13. Edificios del Romea, J. A. Molina, M. Ruipérez A. y V. Pérez A., Murcia, España
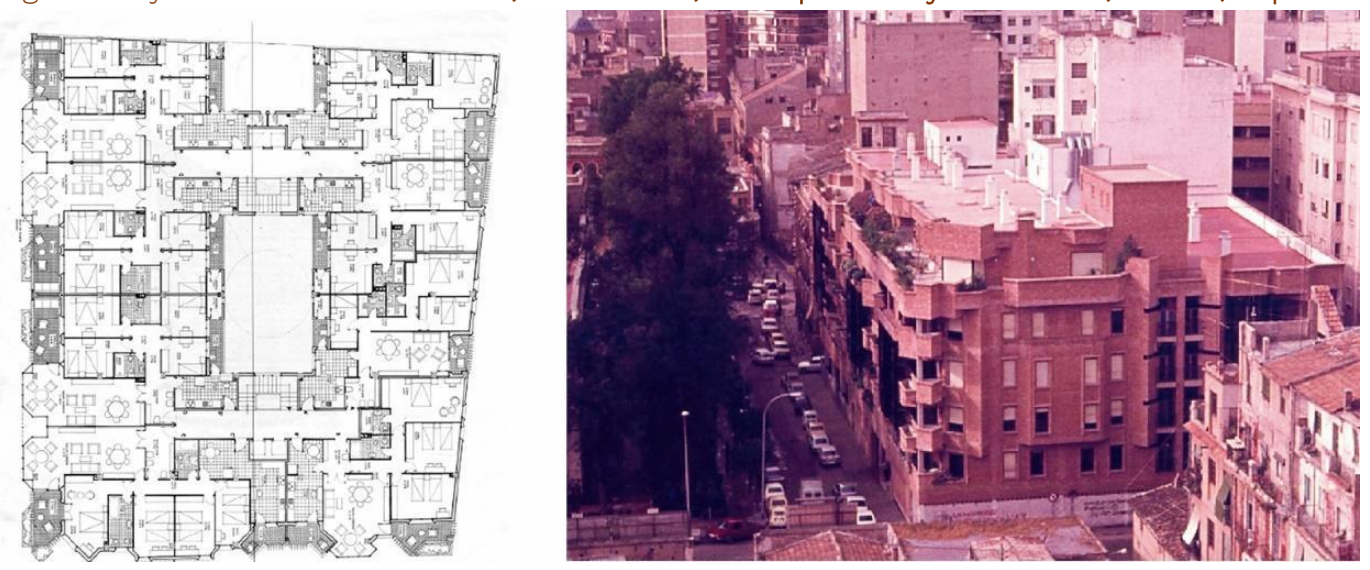

Fuente: APM y AP-jaMS.

ACE, 16 (4.6) CC BY-ND 3.0 ES | UPC Barcelona, España | Construir en el lugar. Juan Antonio Molina Serrano:

hacia el paisaje, la ciudad y el habitar. DOI: http://dx.doi.org/10.5821/ace.16.46.9756 
Ambas fases del Romea reflejan un diálogo abierto entre la tradición y la modernidad, exponiendo una nueva vía de escape a la ciudad y su urbanismo: "un edificio eslabón"4. El programa se distribuye en cuatro tipos de viviendas diferenciadas en torno a un gran patio central. El estudio de los cerramientos y las fachadas se resuelve en un fraccionamiento acusado de los planos extensos y un juego de llenos y vacíos que crean una volumetría o "espacio arquitectónico en sí mismo"5 en donde el elemento mirador es fundamental. El uso del ladrillo refresca la preocupación por dar continuidad a nuevas tradiciones constructivas donde las texturas materiales quedan a la vista y al alcance de la mano, dotando a la arquitectura de cualidades más táctiles. Quizás podamos ver en este recurso empleo del ladrillo cara vista de modo masivo, sobre todo en el exterior - una influencia de la Escuela de Madrid, representada por Gutiérrez Soto en los años 50 y 60 y por Cano Lasso en los 70 y 80.

En el Edificio Arco de Santo Domingo (1976-80), junto al Edificio del Romea y el realizado para viviendas de la Cooperativa del Banco Exterior (1978), en la calle Santa Teresa de Murcia, encontramos otro ejercicio proyectual cercano a la Escuela de Barcelona y algunas de las incursiones y experimentaciones en materiales y texturas de Ricardo Bofill en el tránsito de los años 60 -BachNicaragua-. Situado en un solar irregular (Figuras 14 y 15), se levanta un volumen de cinco plantas y sótano con fachada principal al Teatro Romea, con el que se busca inventar "un eje alternativo ortogonal al del Teatro, dotando al espacio urbano de un cortés duelo de perspectivas” (VV.AA., 2019, p. 316). La planta retoma la idea del patio; pero un patio, esta vez, abierto hacia la que termina siendo la entrada oculta del edificio; se diluye, así, una jerarquía de fachada principal en su frente más urbano. Los salones-estares de las viviendas se generan a partir de una geometría que asocia dos figuras regulares para diferenciar los distintos usos y posibilidades de estas piezas fundamentales de los hábitats. De este modo, una de ellas se asoma a la calle y adopta el cierre de un mirador acristalado -en aluminio - en toda su altura y superficie, alternándose con las terrazas exteriores, que terminan por configurar un plano de fachada que se pliega hacia adentro y hacia afuera, dotando de una cierta plasticidad y expresividad ritmada a la envolvente.

Figuras 14 y 15. Edificio Arco de Santo Domingo, J. A. Molina, Murcia, España

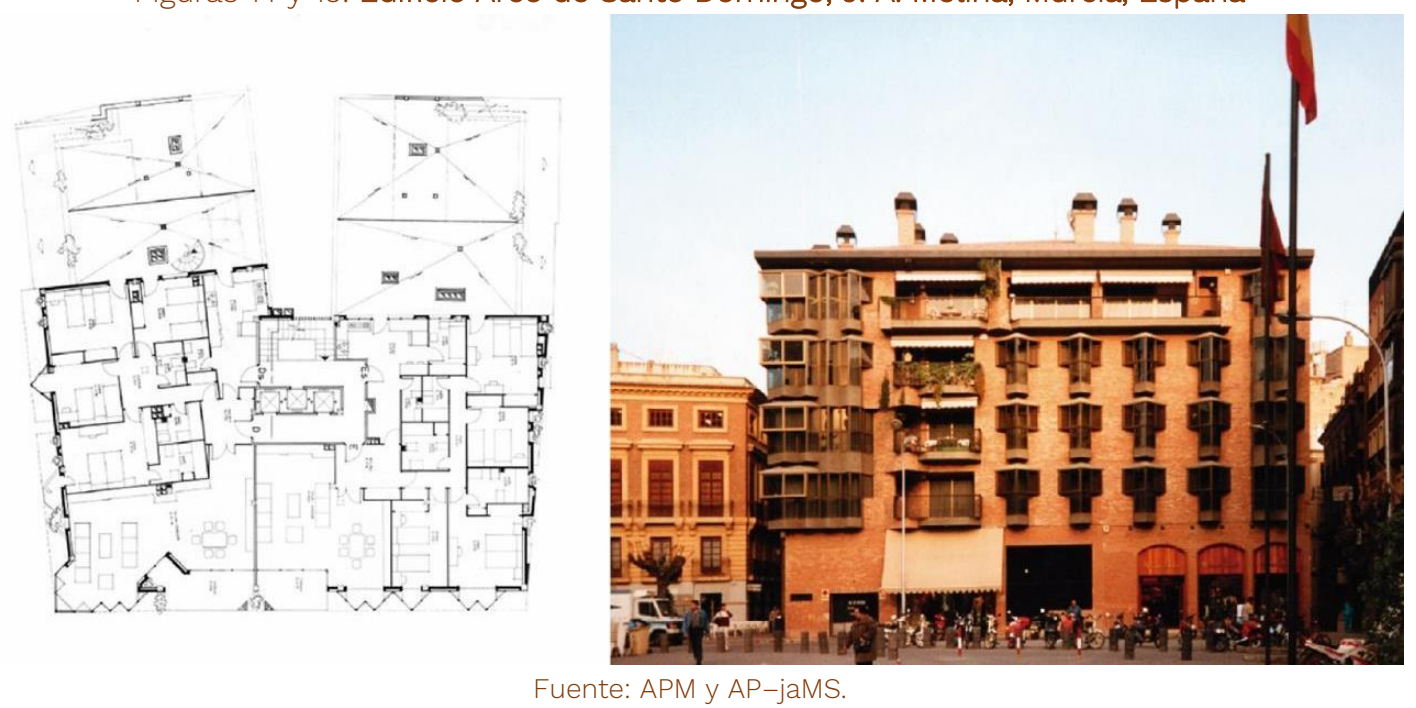

Además, Molina recurre al diseño de las pequeñas cajas de cristal para cada uno de los diferentes miradores -estos rememoran los primeros miradores de finales del s. XIX, de armazón de hierro y planos de vidrio-, con una geometría angular girada 45ํ y una proporción vertical para su mejor

\footnotetext{
${ }^{4}$ Memoria del proyecto, en APM y AP-jaMS.

5 ibídem.
}

ACE, 16 (4.6) CC BY-ND 3.0 ES | UPC Barcelona, España | Construir en el lugar. Juan Antonio Molina Serrano: 
contextualización en la zona histórica de la ciudad, a fin de evitar "el brusco corte de la superficie horizontal"6 y atender al juego pautado de huecos del inmediato y precedente Teatro Romea. No obstante, este mirador no cubre únicamente una aspiración vibratoria de cerramiento y de diálogo con la ciudad, sino también una búsqueda espacial interior que tiene más que ver con el estudio de la planta o espacio doméstico, de sus posibilidades o versatilidad, que con el mero capricho epidérmico. En su exterior, de igual manera, se apuesta por el uso de cubiertas inclinadas y lienzos de fachada en ladrillo cara vista -soga y sardinel- y chapa de acero galvanizado para las chimeneas exteriores y resto de cerrajería. Esta pareja de inmuebles puede agruparse dentro de una fase de su trabajo fuertemente expresiva, que hallará en el estudio detallado de la envolvente su principal investigación. Pronto, sin embargo, esta estrategia se diluirá hacia posicionamientos más abstractos en sus diseños formales, aunque manteniendo las mismas inquietudes en las narrativas espaciales.

Los Centros de Artesanía son, con toda seguridad, la aportación más singular y también la más pertinente síntesis de su producción como arquitecto. Ambos centros, desde sus puntos comunes y oposiciones, explican todo el legado de su arquitectura: Lorca (1985-88), como cuidada atención topográfica: otra 'excavación' que habilita una plaza o 'entorno' en su cubierta atendiendo a las preexistencias históricas inmediatas (Figuras 16 y 17); Murcia (1988-92), desde un volumen blanco (Figuras 18 y 19) que remarca su aparición en un contexto de urbanismo contemporáneo y que prescinde de una huella histórica urbana inexistente para pasar a ser nueva imagen o referente construir el lugar, crear el lugar-, aunque comedido, en esta zona de la ciudad junto al Parque de la Pólvora.

Figuras 16 y 17. Centro de Artesanía de Lorca, J. A. Molina, Murcia, España

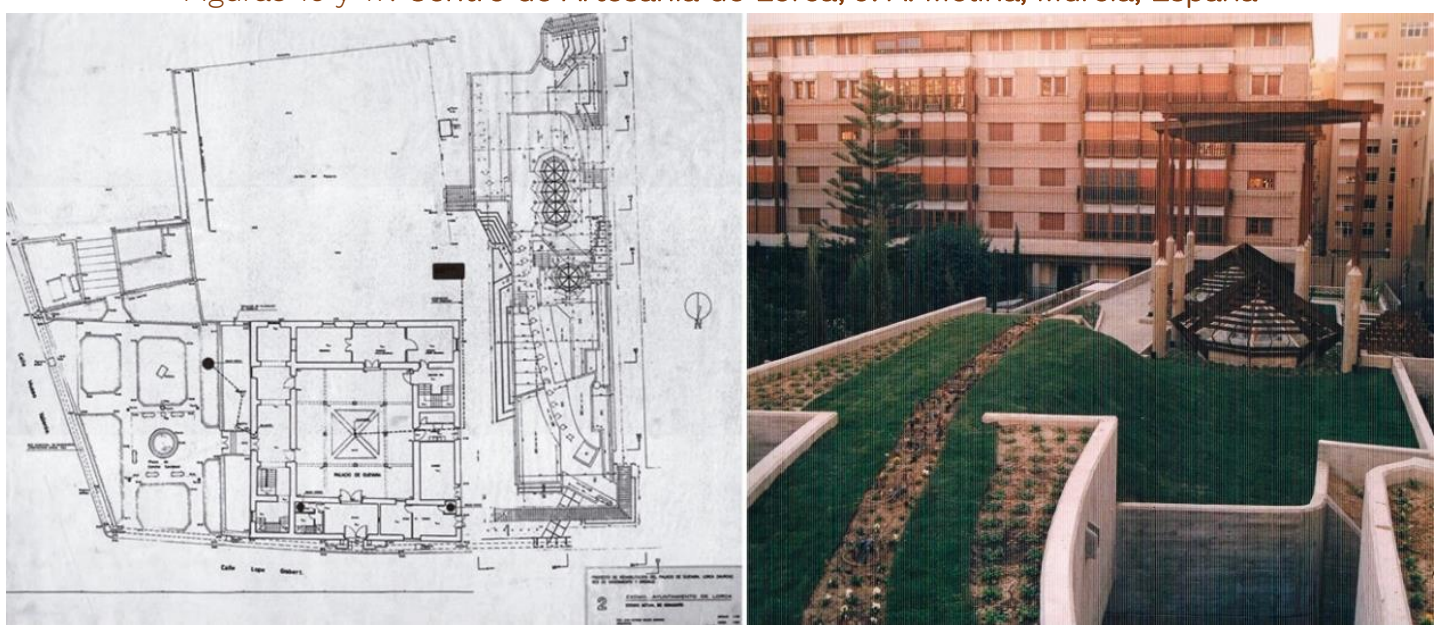

Fuente: APM y AP-jaMS.

Asimismo, son proyectos que nacen de una misma premisa espacial compartida que anuncia, ya de entrada, su disposición a dialogar con el contexto -y su oposición/resistencia a la 'singularidad de los objetos' (Baudrillard y Nouvel, 2000)-: ofrecer un espacio en su interior, que dispone un recorrido jalonado por las piezas más características de la artesanía regional, incorporando en ese itinerario los aledaños próximos de la ciudad, a fin de incluir la calle y el inmediato borde urbano como espacio imprescindible de la acción de los habitantes, de la actividad gremial de la artesanía. Una depresión artificial, en ambos Centros, conduce al usuario hacia abajo a través de la continuidad del pavimento - piedra desbastada de la comarca- que dota a los dos conjuntos de una unidad constante e ininterrumpida entre su interior y exterior: el material del piso y su expresiva textura invitan y ofrecen el paseo, la primera de las conciliaciones sugeridas entre arquitectura y ciudad.

\footnotetext{
${ }^{6}$ Memoria del proyecto, en APM y AP-jaMS.
} 


\section{ACE Architecture, City and Environment}

Figuras 18 y 19. Centro de Artesanía de Murcia, J. A. Molina, Murcia, España

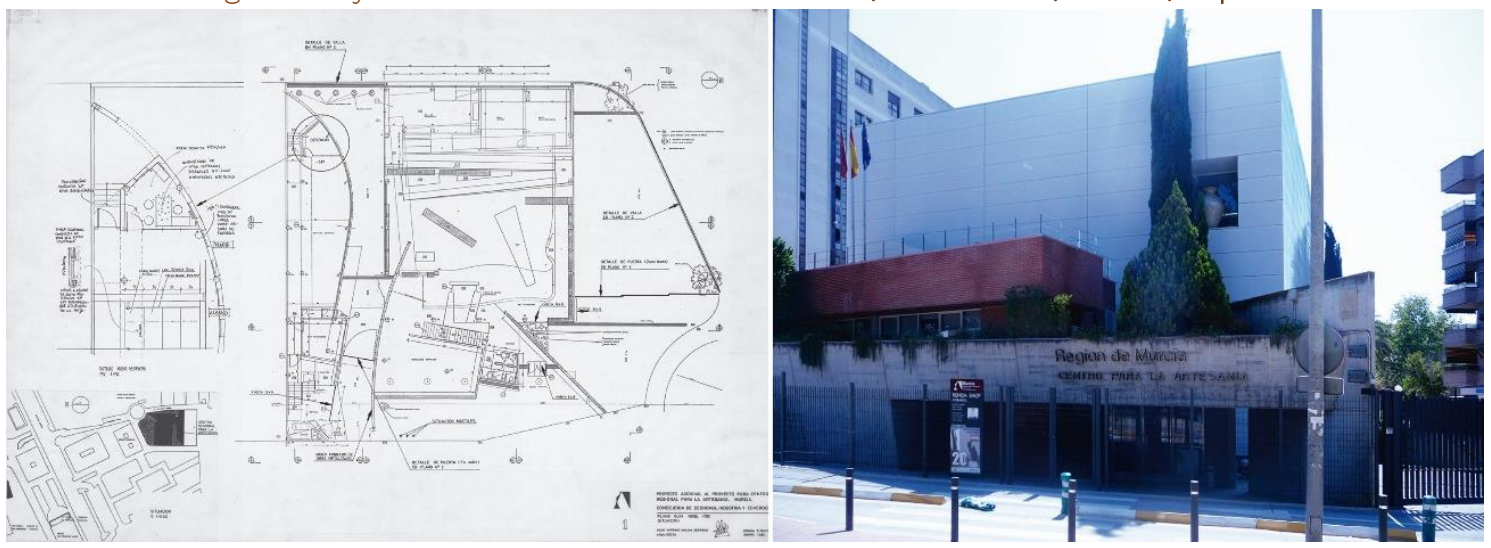

Fuente: APM y AP-jaMS.

La exposición de los objetos de artesanía se desarrolla, en ambos casos, en un itinerario o recorrido que se funde con los materiales de la construcción y el detallado cuidado puesto en el estudio de la luz, llevado hasta sus últimas consecuencias en el Centro de Artesanía de Murcia: plaza, zoco, calles, adarves, nudos, rampas y pasarelas -especialmente en este Centro de Murcia- invitan a contemplar lo que, deliberadamente, busca convertirse en un nuevo lugar dentro del ya existente.

Los Edificios para la Industria Alimentaria HERO (1985-2006) continúan el "lenguaje de los cubos"” que observamos ya en el Centro de Artesanía de Murcia. La etapa, que cubrió la década de los setenta y principios de los ochenta, vino marcada por variadas soluciones tipológicas y de cerramiento Romea y Santo Domingo-, que terminarían por matizarse para encaminar sus prácticas hacia soluciones caracterizadas por la severidad y contención semántica: HERO reflejaría esta nueva alternativa disciplinar (Figuras 20 y 21). El programa nace de la necesidad de habilitar un nuevo espacio de oficinas para la marca comercial, con el fin de ensalzar su conseguida jerarquía dentro del mercado alimentario: "Nunca había trabajado un arquitecto en Hero, siempre delegaban en un maestro de obras. La estética de Hero era muy sencilla, sin ninguna pretensión, a pesar de su gran papel en la industria. El ayuntamiento pidió a Hero que cediera el pico de la proa para poder realizar una rotonda que organizara el tráfico y la entrada. A cambio de ceder ese terreno, querían y proponían hacer oficinas, pero la estética mantenida hasta la fecha se quedaba corta para la 'empresa' que ahora querían realizar. Era la primera imagen de Alcantarilla al entrar. Ellos ya tenían una idea en 'ladrillo cara vista'. Los directivos me propusieron una solución"8.

El contexto de partida, sin embargo, no será solo de orden privado, sino también público, ya que el edificio se encuentra en una de las manzanas más importantes, por su localización, del municipio de Alcantarilla: se trata de la avenida que da la bienvenida y enlaza directamente con el centro del pueblo: "Ninguna manzana de Alcantarilla tiene el valor que esa manzana tiene"9. La solución adoptada -pantallas de hormigón armado donde se intercala un muro-cortina- da como resultado un cubo de cristal que contrasta y, a su vez, refleja el entorno desde su reflexión en el vidrio. Un paralelepípedo de pequeñas proporciones alberga en su interior los despachos y dependencias administrativas de la fábrica. El uso de hormigón de una alta y cuidada factura constructiva se convertirá en un punto distintivo en su arquitectura, desde su pretérita intervención en el COAMU (1979-82) hasta sus últimas obras.

\footnotetext{
7 (Moreno Ortolano, J., comunicación personal, enero de 2015)

8 (Moreno Ortolano, J., comunicación personal, abril de 2015).

9 ibídem.
}

ACE, 16 (4.6) CC BY-ND 3.0 ES | UPC Barcelona, España | Construir en el lugar. Juan Antonio Molina Serrano:

hacia el paisaje, la ciudad y el habitar. DOI: http://dx.doi.org/10.5821/ace.16.46.9756 
Tanto HERO como, con matices, el Centro de Artesanía de Murcia, confirman una nueva estrategia de proyecto en Molina, cercana a intervenciones como la de Gehry en Bilbao: una arquitectura entendida como potenciadora de entornos, creadora de lugares (en este último caso, HERO) que, frente a un perfil industrial degradado y valiéndose de la arquitectura, aportan a la ciudad un nuevo valor urbano.

Figuras 20 y 21. Edificios para la Industria Alimentaria HERO, J. A. Molina, Murcia, España.
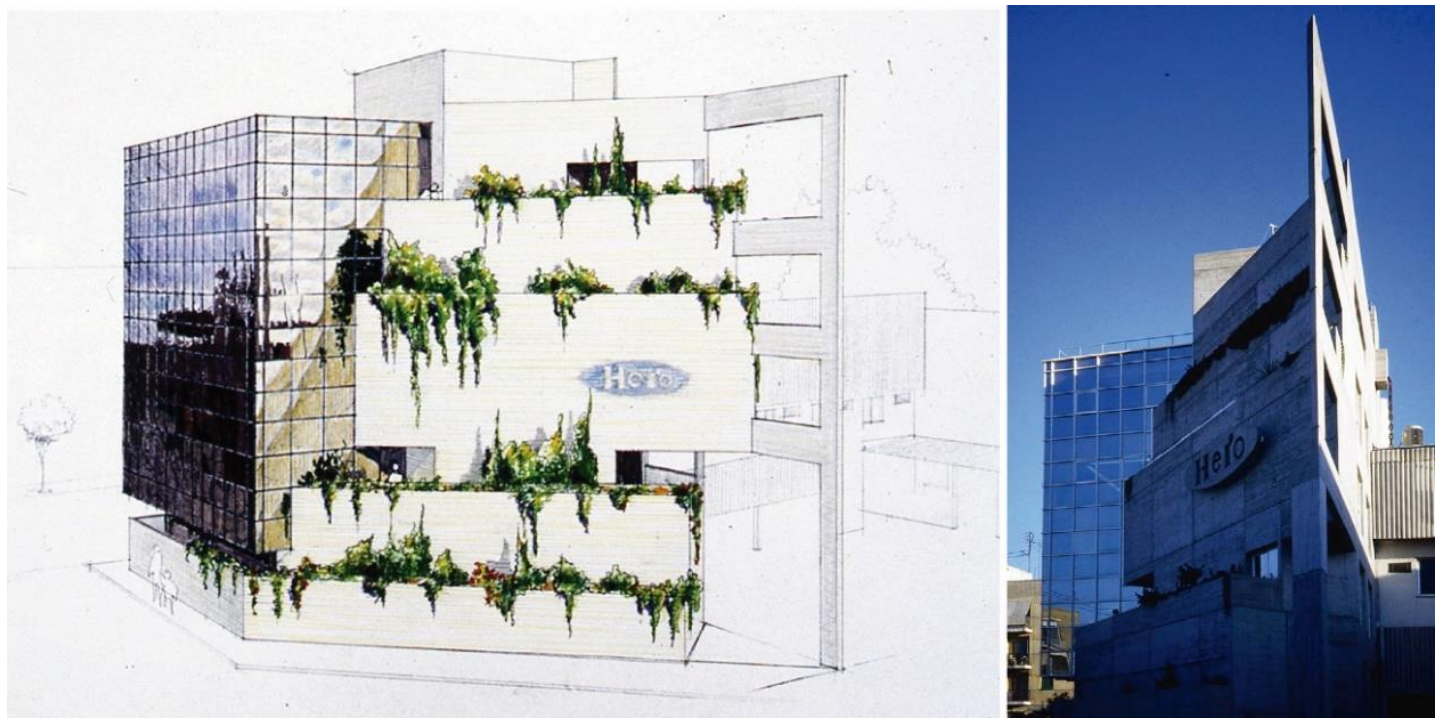

Fuente: APM y AP-jaMS.

Su último proyecto en consideración, el Edificio Anexo de Derecho (2008-12), mantendrá una constante (Figuras 22, 23 y 24) trasladable a la Escuela de Biblioteconomía y Ciencias de la Documentación, la Facultad de Psicología o el Archivo Provincial -todos edificios hermanos y conjuntamente realizados con José Luis de Arana y María Aroca-. Aquí se plantea un bloque que, desde la metáfora construida asociada a la protección del saber y el conocimiento, escoge una senda más callada y arcana con respecto a lo ya visto en sus proyectos urbanos de los años setenta y ochenta ${ }^{10}$.

Se trata de un prisma neutral -cerrado en su envolvente en placa de piedra natural colgada, con lo que se persigue conferir el sentido de unidad material y volumétrica- que busca comedir su implantación y asegura, con dicho fin, la pervivencia del rol protagónico de los edificios universitarios entre los que se encuentra. La propuesta bien podría considerarse otro ejemplo más de lo que Capitel define como "racionalismo ecléctico" (Capitel, 1998, p. 516), o encajar en la lectura que Montaner determina como sintomática en la arquitectura universitaria que cierra la anterior centuria e inicia el siglo XXI: "Es un tema que ha tomado tal predominio en la arquitectura española como es la arquitectura universitaria que continúa la fortuna de la tradición racionalista y funcionalista. Se trata de un tipo de arquitectura que atiende esencialmente al programa funcional y al lugar, y sobre estos dos datos esenciales ensaya una discreta expresividad que surja de la relación del edificio con el medio y de las cualidades de los materiales" (2002, pp. 28-29).

\footnotetext{
${ }^{10}$ La relación y colaboración con Arana y Aroca confirma, de igual manera, este nuevo pulso o tensión poética. Sin embargo, también hay que subrayar que aquel nuevo papel estratégico ya había sido esgrimido por vez primera en HERO y en el Centro de Artesanía de Murcia. Toda la base de este nuevo 'purismo' geométrico, que desde aquí se estira con obras ya más tardías (Escuela de Biblioteconomía y Ciencias de la Documentación, Psicología y Archivo), apunta hacia una nueva manera de contar el proyecto que, eso sí, está más relacionada con la forma urbana: vinculación entre edificio y entorno que, con el posible eclipse de una narrativa espacial, seguida y mantenida bajo las mismas características a las que nos tenía acostumbrados.
} 


\section{ACE Architecture, City and Environment}

e-ISSN 1886-4805

Figuras 22, 23 y 24. Edificio Anexo de Derecho, J. A. Molina, J. L. de Arana y M. Aroca, Murcia, España

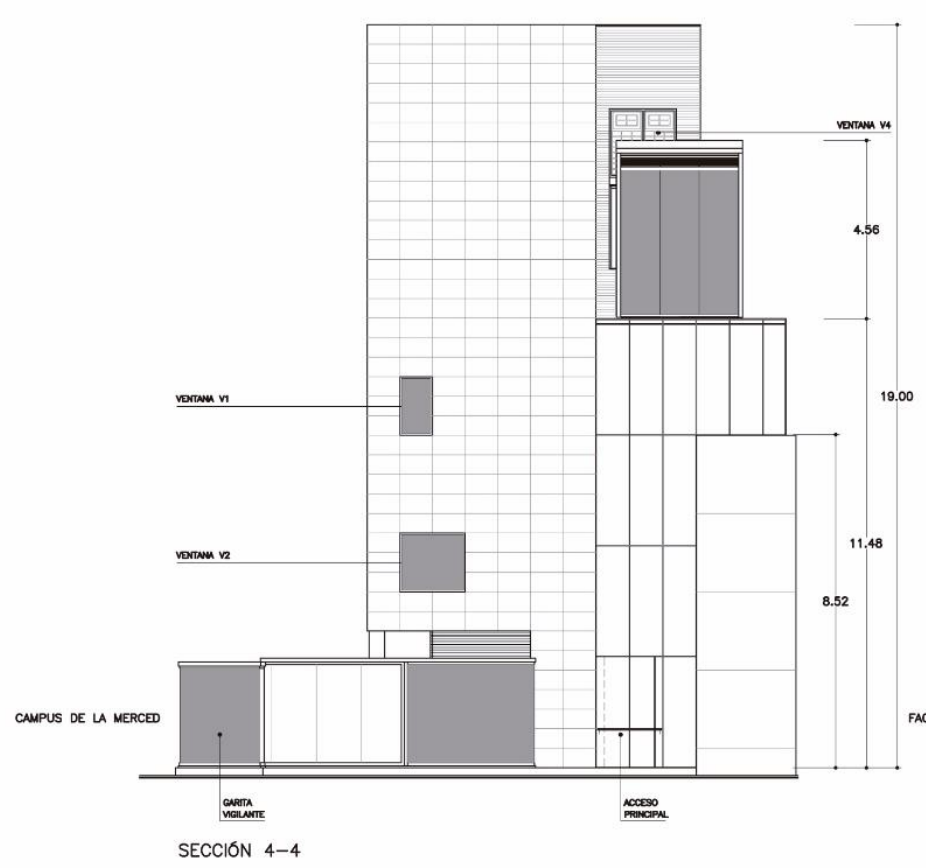

FACULTAD DE DERECHO
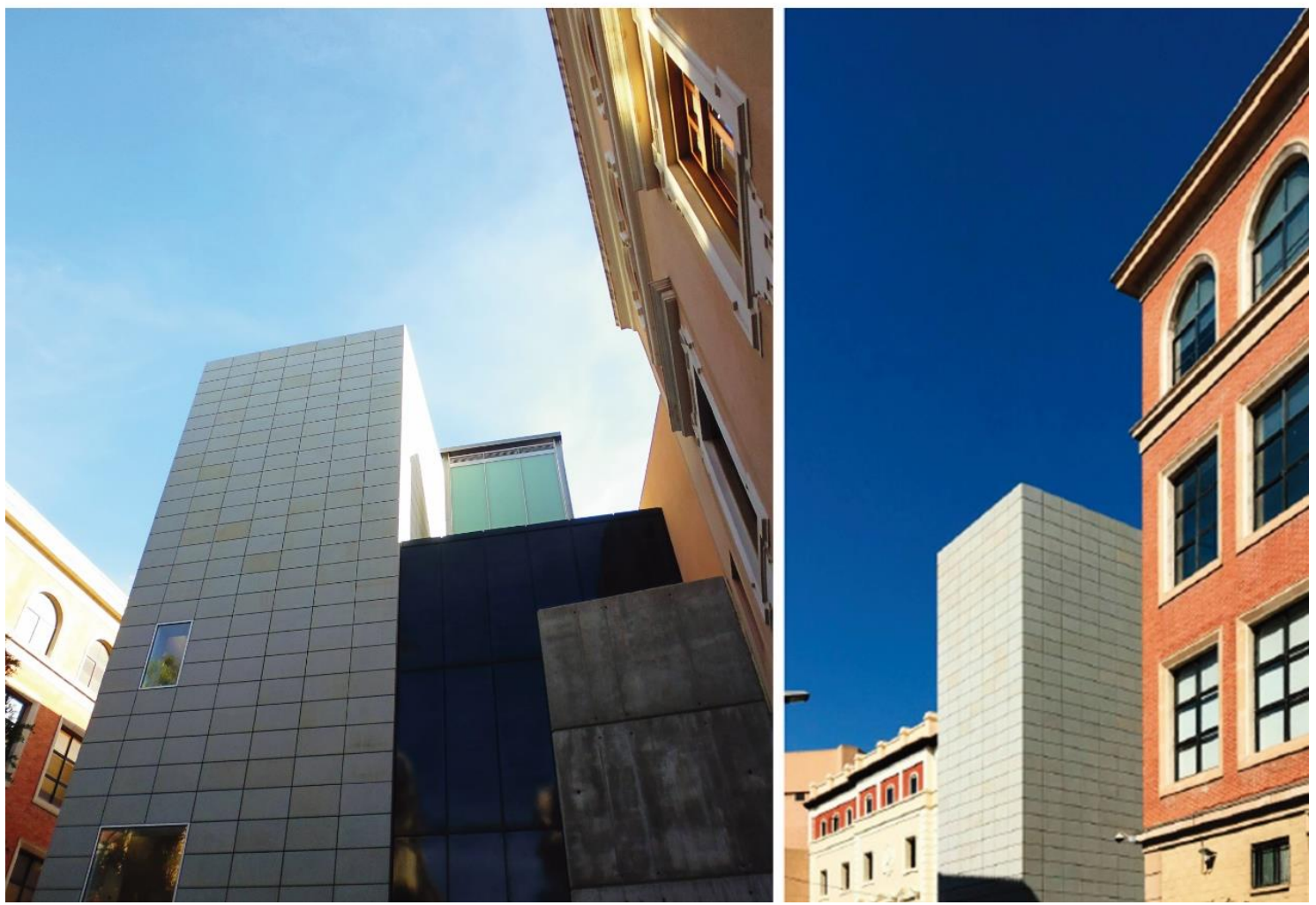

Fuente: APM y AP-jaMS. 


\section{Hacia el habitar. La arquitectura como lugar social}

Prácticamente todo su trabajo, desde el inicio de su carrera, permanece unido a una necesidad vital: crear ciudad11, crear lugares, lugares en toda su dimensión social y que podrían muy bien agruparse en torno a las tres categorías que, según Augé (2004), lo definen. La protección de la identidad, la historia y los espacios sociales de relación son variables que, en Molina, juegan un papel crucial dentro de la disciplina de la arquitectura: no descuidar al habitante, al morador de la ciudad; ese 'eslabón' perdido que en tantas ocasiones se menosprecia u olvida. Sobre esta cuestión, Cristián Fernández Cox apunta: "Esta relación primordial forma-habitante, se ha venido diluyendo en la mente y consideración de los arquitectos" (Cox, 2000, p. 26). Para Molina, el cuidado y atención de esa relación integra el principio generatriz de la elaboración proyectual: "El programa y las personas son lo primero para míp'12.

Un caso singular, conectado a lo señalado, lo encontramos en el Colegio Santa María del Carmen en colaboración con V. Pérez Albacete y M. Ruipérez Abizanda (1973-75) -, (Figuras 5, 25, 26, 27 y 28). Se trata de un proyecto muy vinculado a una herencia moderna que demuestra, también en su caso, la continuidad de un fenómeno reivindicado en España: la persistencia de lo moderno y su revalorización. No podemos olvidar que, precisamente durante estos años, se retoma un entusiasmo 'saludable' y afín a la arquitectura moderna, tal y como queda reflejado - por citar alguna de las fuentes próximas a este debate- en las palabras de María Teresa Muñoz: "Por nuestra parte, hemos de reconocer que tanto estas afirmaciones de la vigencia y vitalidad de lo moderno dentro de la arquitectura actual como la entrada sin trabas en las obras construidas de rasgos formales propios de la arquitectura moderna sólo puede tener efectos saludables para la arquitectura de nuestra época, ya que no conducirá en ningún caso a una simple recuperación, sino que entrará a formar parte y a vitalizar una situación indudablemente muy lejos ya de aquella otra marcada por la seguridad formal que presidió la arquitectura moderna e hizo posible la existencia de un único Estilo Internacional. Y, a la vez que compartimos este interés por todo lo relativo a la arquitectura moderna en cuanto referencia fundamental de la arquitectura contemporánea, pensamos que, desde una óptica bastante lejana a los primeros momentos de lucha contra la modernidad, también el Estilo Internacional puede ser hoy visto de un modo muy distinto a como se vio en los años sesenta" (Muñoz, 1982, p. 56). El Colegio Santa María del Carmen participa de una misma recuperación y seguimiento, lo cual se verifica en la gramática o composición del edificio; en su cerramiento o envolvente: ventana longitudinal, expresión y manifestación de un ideal industrial, modulación, contención semántica o esencialismo geométrico y, por igual, en la alusión directa -comportamiento estructural- del uso de pilotis que elevan algunos de los volúmenes principales del Colegio. De la misma manera, el edificio tributa con respecto a uno de los tipos compositivos centrales que la arquitectura moderna ha utilizado como fuente inagotable en sus métodos de proyecto: el patio. Es aquí, desde una decidida revisión o alternativa ya no hegemónica, sino matizada de la modernidad, donde también Molina confirma la versatilidad de un modelo y su puesta en valor. Sobre esta revaloración del tipo patio como constante histórica y recurso para la arquitectura, Capitel puntúa: "El patio no es tan sólo un elemento totalmente principal en la historia de la arquitectura, desde la antigüedad hasta la edad moderna, como todos sabemos; es también la base de un verdadero sistema de composición, el soporte de un modo de proyectar tan universal como variado" (Capitel, 2005, p. 6). Al mismo tiempo, este colegio público congrega otro elemento compositivo igualmente experimentado por la arquitectura moderna: el pabellón (Martí, 2008). Ambos, patio y pabellón, constituyen la base de proyecto que organiza todo el conjunto.

\footnotetext{
${ }^{11}$ Postura que coincide con la crítica mantenida por Bohigas frente a la incontinencia urbana de la ciudad contemporánea: una interpretación que pretende reivindicar el valor y recuperación de los centros urbanos, en detrimento de las políticas de expansión periféricas (2004).

12 (Moreno Ortolano, J., comunicación personal, noviembre de 2015).
} 
Figuras 25, 26, 27 y 28. Colegio Santa María del Carmen, J. A. Molina, M. Ruipérez Abizanda y V. Pérez Albacete, Murcia, España

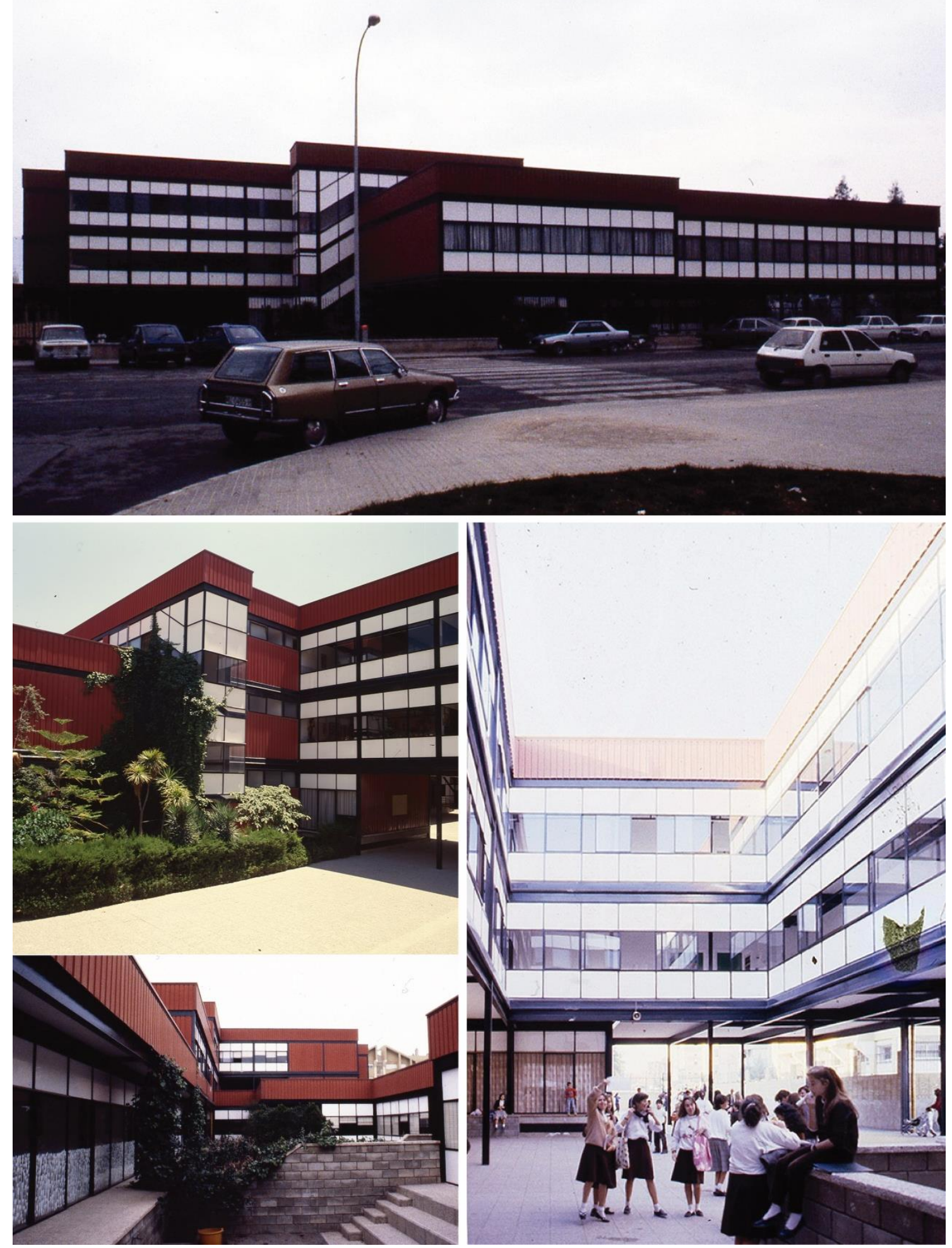

Fuente: APM y AP-jaMS. 
El tipo pabellón favorece la visión panorámica y extensiva - se trata de un edificio originalmente situado en medio de la huerta-, mientras que el patio no solo organiza analíticamente la planta programa y funciones-, sino que termina favoreciendo un propio y exclusivo microclima -ambiental y natural- que define y consolida muy distintas formas de apropiación sobre la parcela y el campo circundante en el que se implanta el edificio: porosidad y asociación revalidan las lecturas de los edificios tapiz -Alison Smithson, Alexis Josic, George Candilis, Shadrach Woods, entre otros-, en donde patios, aulas y corredores habilitan un flexible contenedor apaisado, horizontal, formado por un conjunto de patios de diferentes dimensiones y tratamientos que se apoyan en una estructura reticular (Montaner, 2008). Lo más significativo, en lo relacionado al eje central que aquí se explora, es la forma en que el patio, en su diversidad, resume un ideal social que reverberará en todo el trabajo de su autor: el patio como lugar estacional -contacto directo con una naturaleza domesticada y cercana-, recreativo, impulsor de la actividad placentera del habitar; del crecer, del aprender, del vivir y soñar de los niños. Obra, esta, muy temprana, constituirá la antesala de una actitud ética, teóricamente implícita, que ya no será abandonada.

Siguiendo con esta perspectiva, debe incluirse el edificio residencial para la Cooperativa del Infante Don Juan Manuel en Murcia (Edificio Infantes, 1980) (Figuras 29 y 30), que termina por hacerse eco de un tipo tradicional y popular, revisitado, como es el de los claustros y las antiguas corralas; y es que también aquí se propicia la sociabilidad, gracias al tránsito de las personas que acceden a las viviendas desde los espacios corredores que envuelven el gran patio central -cualificando y potenciando el devenir y vivir cotidiano (Montaner, 2015)-. Este caso concreto, se resuelve desde una combinatoria en la que el patio y los corredores de circulación se sitúan como núcleo central de la composición, al punto que participan o se unen al mismo tres figuras irregulares de acusada plasticidad, que vemos expresarse desde el movimiento y fraccionamiento de la envolvente, con el propósito de aportar un correcto soleamiento y la adecuada ventilación de las viviendas.

Figuras 29 y 30. Edificio Infantes, J. A. Molina, Murcia, España
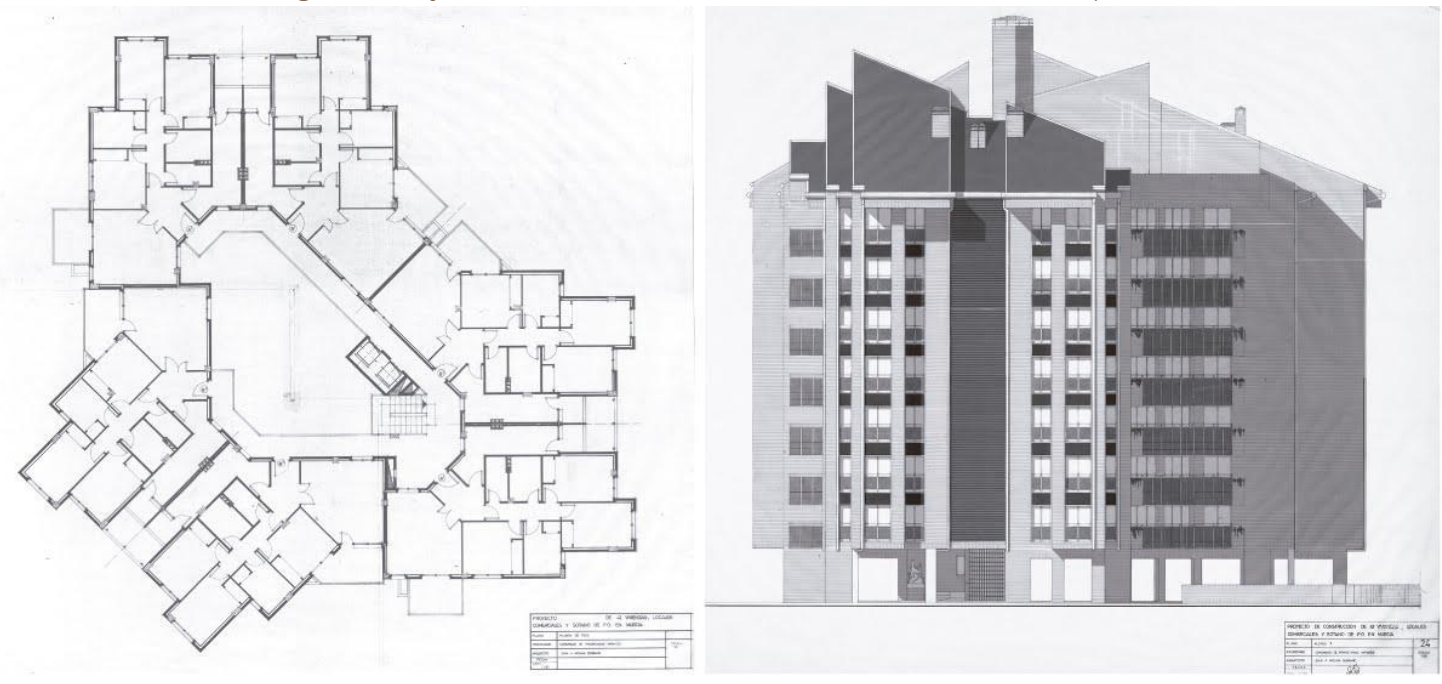

Fuente: APM y AP-jaMS.

Son quizás otros dos proyectos, uno frustrado y otro realizado, los que resumen, ya en el espacio público, la aspiración final de su mensaje: el de la Plaza Santo Domingo (1988) y la intervención en la Plaza Santa Isabel (1998-2000). Los croquis iniciales de Santo Domingo (Figuras 31 y 32) recrean naturalezas inventadas que revisitan la idea de los hortus conclusus, realizados más tarde en la Plaza de Santa Isabel y también en anteriores ocasiones, como en el Centro de Artesanía de Lorca. Un programa variado de zonas y pequeños teatros al aire libre habilita espacios para la representación 
escénica y la reunión pública a través de la revitalización de los antiguos refugios de la guerra civil enterrados en el subsuelo (VV.AA., 2019). El carácter colectivo, ya sugerido en sus dibujos, evitará, decididamente, lecturas contemporáneas, mucho más higiénicas y ‘formales'. La configuración de los recorridos y la abundante vegetación subrayan la importancia de una búsqueda urbana más humanizada y fuertemente influida por su paralela formación teatral, al tiempo que nos recuerdan que "El fundamental cometido mental de la arquitectura es el alojamiento y la integración" (Pallasmaa, 2016, p. 11).

Figuras 31 y 32. Plaza Santo Domingo, J. A. Molina, Murcia, España
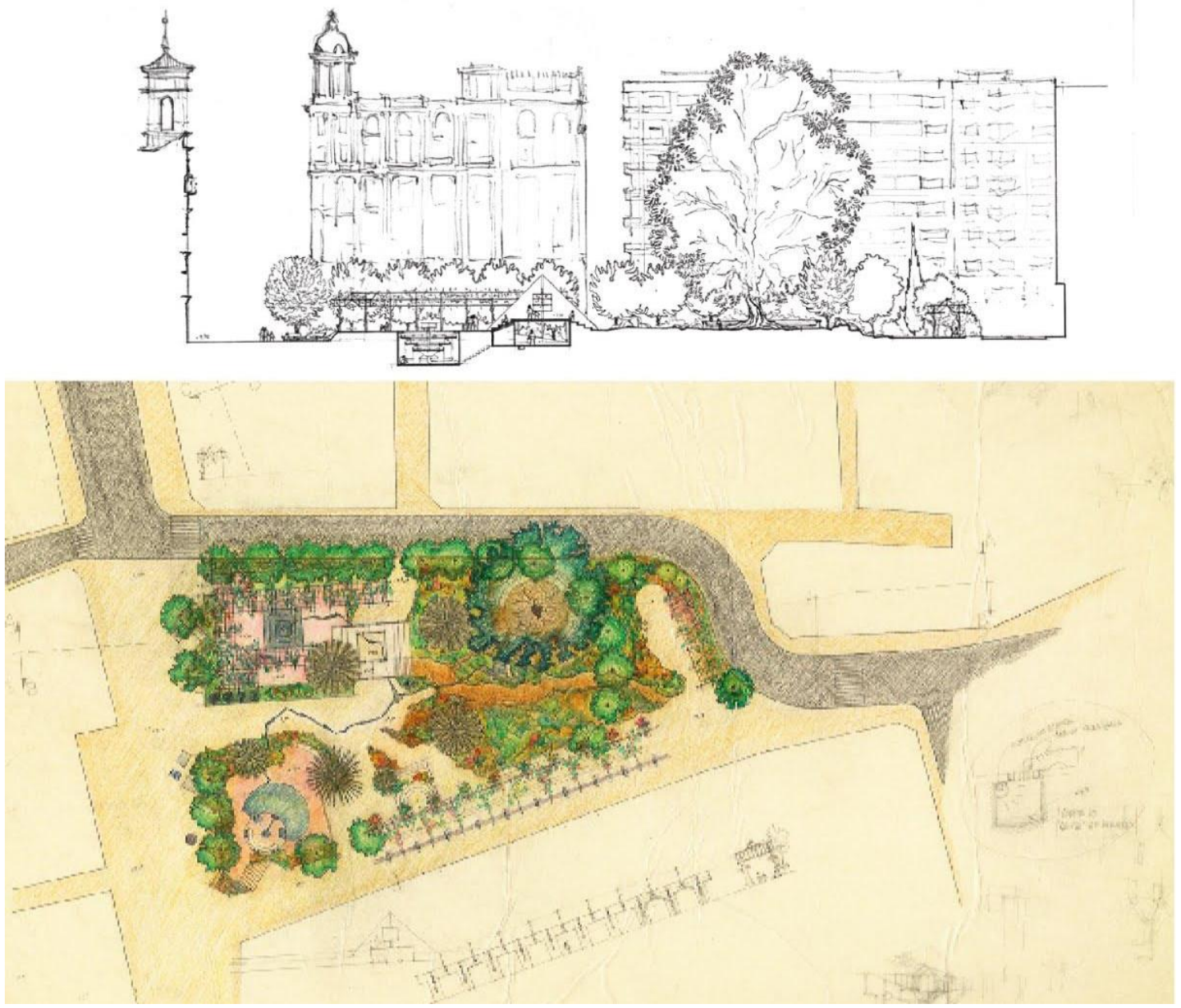

Fuente: APM y AP-jaMS.

Santo Domingo y Santa Isabel participan de una solución basada en un aspecto esencial: dotar a la ciudad de una zona verde que vuelve a recuperar las enseñanzas que barrios como Vistabella, realizados por Daniel Carbonell, habían ofrecido en la periferia de Murcia en los años cincuenta. No obstante, dicha correspondencia debe contemplarse desde el paralelismo social de las intervenciones: apostar por la recuperación de las rutinas sociales de la calle; revalorizar los usos y participación de la vecindad en el espacio público y recrear escenarios acompañados de una importante presencia de vegetación y arbolado que atienda a las condiciones climáticas y la geografía. Se trata de rescatar el espacio público para los vecinos - desterrando los coches-, a fin de fortalecer la actividad pedestre, el caminar o deambular, la lentitud; descanso urbanita y relaciones colectivas; y, nuevamente, la apropiación de los lugares y el 'derecho a la ciudad'. Desde un breve apunte y

ACE, 16 (4.6) CC BY-ND 3.0 ES | UPC Barcelona, España | Construir en el lugar. Juan Antonio Molina Serrano: 17 hacia el paisaje, la ciudad y el habitar. DOI: http://dx.doi.org/10.5821/ace.16.46.9756 


\section{ACE Architecture, City and Environment}

confirmando esta misma senda, se contempla también su proyecto para la remodelación -no realizada- de la vía urbana de la Calle Teniente Flomesta y la Plaza de Cruz Roja (2002) (Figuras 33 y 34), en la ciudad de Murcia: una declaración más que pretende regalar la ciudad a los habitantes, con el fin de crear -tal y como se constata históricamente en la cultura urbana de los pueblos mediterráneos- la sensación de que la calle pueda convertirse en la prolongación del espacio del salón o epicentro del hogar: síntesis, nuevamente, de su búsqueda.

Figuras 33 y 34. J.A. Molina en su estudio, Proyecto para la remodelación del espacio público de la Calle Teniente Flomesta y la Plaza de Cruz Roja, J. A. Molina, Murcia, España
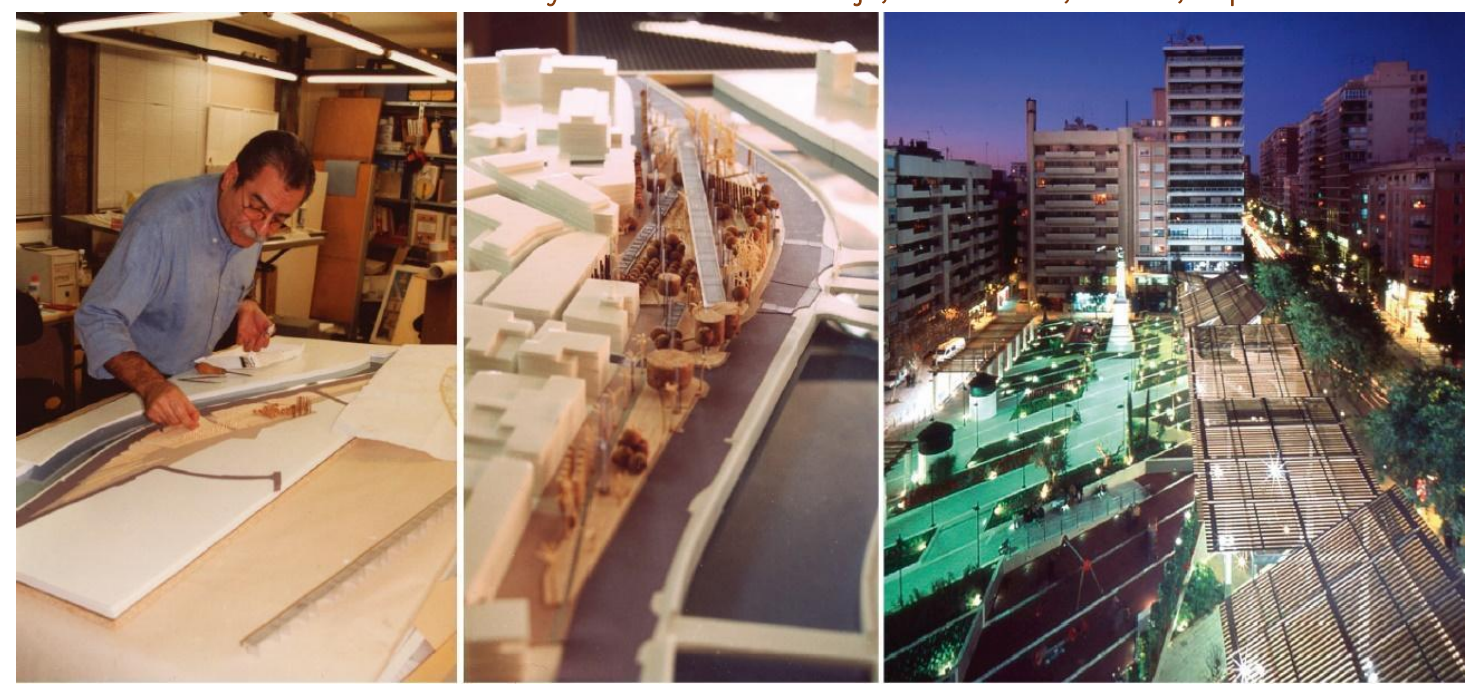

Fuente: APM y AP-jaMS.

Con Santa Isabel (Figuras 35, 36 y 37), Molina conseguirá una de sus más afortunadas intervenciones en la ciudad, en la cual los centros pretenden seguir siendo los 'lugares' posibles y practicados (De Certeau, 1999). Con ella concluye la unificación de las Plazas de Santa Catalina, las Flores y San Pedro (1994-96), también del autor, y se determina un conjunto con vocación de unidad. Este proyecto, conjuntamente con el no realizado de Santo Domingo, se distanciará de los "egoísmos de cemento" preconizados por Stefano Boeri (2011, pp. 9-12), al buscar, frente a la 'anti ciudad', recobrar el valor histórico, relacional y comunicacional de los centros urbanos. Conviene citar, para entender mejor la estrategia de las plantaciones verdes de la Plaza de Santa Isabel, que bajo el jardín ya existía y existe un aparcamiento subterráneo que condicionó la solución.

Figuras 35, 36 y 37. Intervención en Santa Isabel, J. A. Molina, Murcia, España.
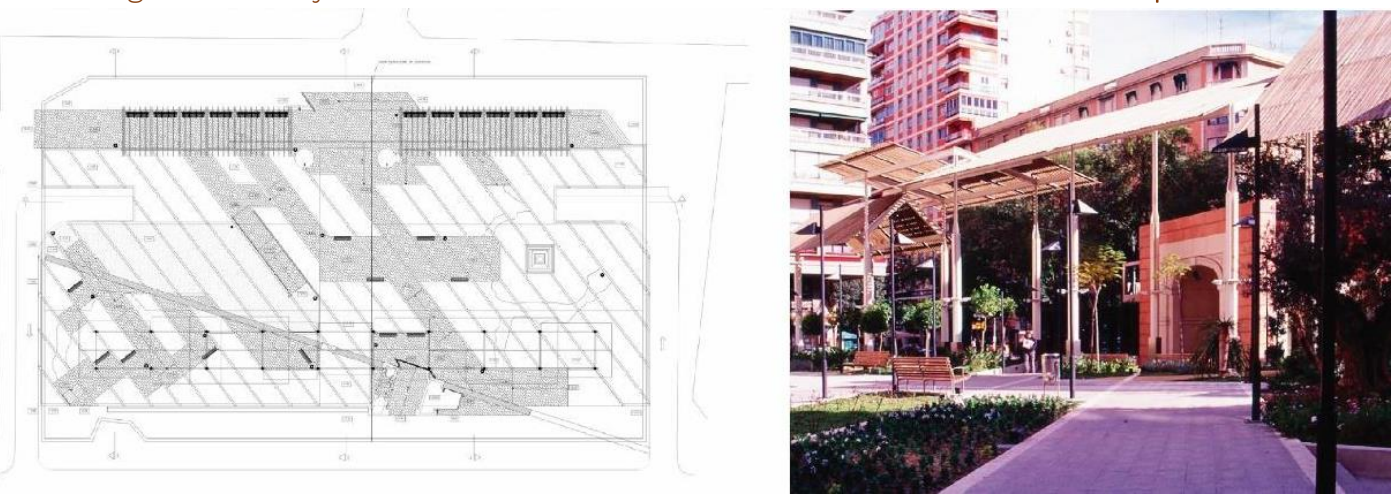

Fuente: APM y AP-jaMS.

ACE, 16 (4.6) CC BY-ND 3.0 ES | UPC Barcelona, España | Construir en el lugar. Juan Antonio Molina Serrano: 
Las antiguas depresiones de la anterior plaza se aprovechan aquí para generar los grandes maceteros o parterres de tierra en donde se ubicará toda la vegetación, estudiada con sumo detalle y en colaboración con los jardineros, a fin de incluir especies -tanto arbustos como árboles- en donde el crecimiento de las raíces se distribuya horizontalmente. La arriesgada decisión -fuera de cualquier conformismo y sin afectaciones de estilo o tributos pasajeros- ha corroborado, con el devenir de los años y el crecimiento de todo lo plantado -indispensable para entender el verdadero alcance de la intervención y la función matizadora, orgánica y ambiental del conjunto- sus cualidades urbanas y afortunado desenlace, compensando sobradamente las dudas iniciales y las 'críticas literarias'.

\section{Conclusiones abiertas}

Tras haber expresado la disposición a dialogar y a relacionarse con el lugar -heterogénea, por tantoque la arquitectura de Juan Antonio Molina desprende, conviene detenerse en unos últimos titulares. Su trayectoria se inicia desde una escucha y respuesta sobre el lugar que, inicialmente, participa de cierta validación de las corrientes orgánicas, así como de las enseñanzas provenientes de la Escuela de Madrid y de algunas reminiscencias de la Escuela de Barcelona. Estas resonancias quedarán expuestas en las formas 'paratácticas' de sus Edificios del Romea y Arco de Santo Domingo, bajo la lectura atenta del contexto, pero sabiéndose convencidos de su tiempo y decidida apuesta por la arquitectura. Es justamente en este momento, cuando su acción profesional convive con gran parte de los referentes que también están siendo compartidos por sus compañeros de profesión. Carvajal, Fullaondo, Corrales y Molezún, Oíza, Fernández Alba, Higueras y Miró y, más tardíamente, Moneo, vienen a preparar el fértil territorio del cual parte la propuesta de Juan Antonio Molina. En un primer momento, su arquitectura vivirá un despertar y entusiasmo híbrido por lo orgánico y lo moderno para, durante el transcurso de su recorrido y trabajo, acabar diluyendo ambas influencias -especialmente la primera-. Es ahí donde, con obras como el Centro de Artesanía de Murcia y Hero, su arquitectura irrumpe en un punto más sobrio y comedido, especialmente en el tratamiento de las envolventes de sus edificios: "Era un momento en que me dio un ataque de simetría y clasicismo"13. Sus intervenciones urbanas se vuelven, a partir de entonces, más neutrales, discretas y austeras en su aparición, hasta el punto de identificarse, tal y como el propio autor describe, con el "lenguaje de los cubos"14. Dicha aproximación culmina o queda refrendada en el Edificio Anexo de Derecho y en toda la familia de proyectos que van desde la Escuela de Biblioteconomía y Ciencias de la Documentación hasta la Facultad de Psicología y el Archivo Provincial Histórico de Murcia. Sin embargo, no por ello sus trabajos se distancian del lugar, sino que parecen haber encontrado, "en la pureza de las formas" 15 , las volumetrías silenciosas y cierta abstracción formal, una más afortunada relación con los entornos, los cuales se pretende ahora diferenciar, ensalzar y transformar -construir el lugar y crear el lugar-. El Centro de Murcia y, sobre todo, los Edificios para la Industria Alimentaria Hero en sus distintas fases señalan esa nueva frontera traspasada en su trabajo que, paralelamente, se encamina a situar estos conjuntos como referentes legibles e identificables del imaginario cultural colectivo (Lynch, 2008).

No obstante, parece aquí oportuno detenerse -a pesar de la heterogeneidad de su trabajo, propiciada por la escucha del lugar- en unos temas comunes o invariables, a través de los cuales se podría identificar una 'iconografía reconocible' en este profesional. En primer lugar, su producción permanece unida hasta lo más hondo a otra esencial fuente de inspiración: el teatro. En efecto, el aprendizaje y experiencia adquirido en esta otra disciplina artística añade a sus métodos de proyecto y composición un ingrediente determinante, que va a ocupar en su trabajo un lugar recurrente y válido

\footnotetext{
13 (Moreno Ortolano, J., comunicación personal, enero de 2015).

14 ibídem

15 (Moreno Ortolano, J., comunicación personal, noviembre de 2015).
}

ACE, 16 (4.6) CC BY-ND 3.0 ES | UPC Barcelona, España | Construir en el lugar. Juan Antonio Molina Serrano: 
(Moreno, 2021), tanto al inicio como al final de su carrera -aun a expensas de la ruta escogida posteriormente, más racional, pero que, no por ello, anulará de sus incursiones el vivo sentimiento de lo escenográfico que sigue pretendiendo "dentro de lo racional hacer sorpresivo el tema"16-. La sorpresa y un relativo carácter lúdico y sincrético podrían perfectamente considerarse estrategias de proyecto que vienen ya canalizadas desde su formación teatral, inseparable de su 'escenario' vital y profesional. Asimismo, y por citar un ejemplo, resultan reveladores los tratamientos escogidos por el autor para los umbrales de paso, las esclusas, los espacios intermedios o las circulaciones verticales, en donde se detecta un semejante procedimiento de actuación: significación de la ubicación espacial de los mismos, familia similar de materiales utilizados, valoración expresiva de las texturas materiales de estos lugares de tránsito o paso y, en definitiva, un intento por aportar, desde su arquitectura, relaciones más vinculadas al tacto que involucren al visitante desde todos sus sentidos.

Por último, se reconoce un método de proyecto persistente en su obra ${ }^{17}$ relacionado con la 'diagonalidad'18. Tanto en los conjuntos residenciales - Guardamar-como en los domésticos e íntimos -Casa Serrano-, pasando por edificios como el Centro de Artesanía de Murcia y en sus operaciones en los espacios públicos -especialmente el de Santa Isabel-, parece distinguirse el uso de esta ley directora o método de proyecto (ibídem) que facilita el agrupamiento y ordenación de la planta. Así pues, todas ellas pueden considerarse características comunes que intervienen con mayor o menor intensidad en gran parte de su trayectoria profesional.

Finalmente, podría apuntarse que todas las escalas tratadas interactúan desde un mismo núcleo proyectual: tanto su orientación hacia el paisaje como sus intervenciones en la ciudad vienen a aliarse desde la oportunidad que supone, para Molina, ejercer la arquitectura como elaboración de los espacios de la vida del ciudadano. Será el Transformador, en su génesis, quien dicte la primera declaración -implícita en este caso y puntualmente simbólica-, pues su construcción exalta la dignificación del trabajo artesano y la tierra o huerta en donde este se realiza. Seguirá en otras piezas tempranas, como el Colegio Santa María del Carmen, declarado testimonio de los repuntes de la modernidad de los años 50 revisitados, pero también escenario de sus preocupaciones sociales y de los retos ya asumidos y consignados internamente por su arquitectura. Y se hará más notorio aún en Guardamar, desde la construcción de un espacio de relación y comunidad que se asocia con su ambiente más próximo e inmediato; aspecto, este último, sintomático de las intervenciones populares urbanas mediterráneas (Cortés Pedrosa, 2018).

Esta actitud la comparte, igualmente, en sus incursiones en la ciudad, ya que, desde su afiliación con las preexistencias, pero también desde el intento por dotar a la misma de una nueva identidad, valor o 'legibilidad', sus acciones regeneran, revitalizan y aportan una nueva caracterización a los escenarios existentes, a la par que habilitan espacios públicos para el disfrute y esparcimiento. Todas las escalas, por tanto, se despliegan desde un mismo centro teórico o proyectual: humanizar la arquitectura desde la atención a los lugares en los que se da y desarrolla el habitar, buscando estimular la interacción social: un modo de hacer o pensar que para Molina será frecuente. Por eso mismo, puede afirmarse -declaración que, aún hoy día, gravita intermitentemente en la disciplina- que su trabajo se desmarca de aquella apreciación o "sospecha de que el lugar socava la libertad del proyecto moderno, introduciendo dimensiones paralizantes y anticuadas” (Thornberg, 2011), al tiempo que parece haber rebasado los tres prejuicios que Thornberg señala como lastres disciplinares -en especial, aquel que identifica a la arquitectura como una actividad profesional ajena y aislada de su

\footnotetext{
16 ibídem

17 Cuestión que se analiza con mayor profundidad en un trabajo de investigación paralelo y complementario (Moreno, 2021).

18 La diagonalidad, tal y como indica Joel Levinson en sus estudios, resuena en distintos episodios de la historia de la arquitectura y se hará especialmente relevante en la arquitectura moderna y en la segunda mitad del siglo XX (Levinson, 2020).
}

ACE, 16 (4.6) CC BY-ND 3.0 ES | UPC Barcelona, España | Construir en el lugar. Juan Antonio Molina Serrano: 20 hacia el paisaje, la ciudad y el habitar. DOI: http://dx.doi.org/10.5821/ace.16.46.9756 
entorno, exenta de adhesiones, vínculos o relaciones-. La obra o trabajo de Juan Antonio Molina Serrano podría, muy bien, incluirse dentro de la categoría que entiende la arquitectura como "un puente (cronotopo) entre construcción y habitar, de un lado, y autor y sociedad, de otro, haciendo así posible la construcción de un nuevo "lugar" (ibídem, p. 3). Son los Centros de Artesanía, muy particularmente, los que mejor pueden adscribirse a esta lectura y resumir su consonancia con ella: Lorca, como solidaria intervención en un entramado urbano de relevante valor histórico, al que conviene asistir desde un volumen que se entierra para alojar el programa bajo tierra. El lugar ya posee una definición notable, razón por la cual la arquitectura parece, fundamentalmente, plegarse a los atributos ya existentes. Y Murcia, como emplazamiento que exige una nueva identificación, la construcción de un nuevo entorno, motivo por el cual el edificio busca convertirse en la renovada imagen de esta zona de la ciudad. Ambos centros se diseñan bajo una escenografía sutilmente formulada en Lorca y mucho más explícita en Murcia; y procuran, definitivamente, constituir ese 'puente' o 'cronotopo' entre arquitectura y habitar: en el primer caso, a partir de una plaza o jardín aterrazado, ubicado en la cubierta; en el segundo, desde un singular 'escenario' interior, proyectado y embebido en los límites próximos urbanos en los que tiene lugar -al igual que en su interior- la feria de la artesanía. Uno y otro, en conclusión, buscan fomentar el intercambio y la socialización desde dos lecturas distintas, pero que aspiran al mismo fin.

En definitiva, su recorrido profesional debe ser leído desde la unión con los habitantes y las afiliaciones artísticas y escénicas que vienen a intercambiarse y mezclarse en su arquitectura (Moreno, ibídem). En ese cruce o atmósfera se rastrea su aprendizaje, recogido en la Escuela de Arquitectura de Madrid y bajo el magisterio de Carvajal y Fullaondo, así como en sus años como profesor en la Escuela de Artes y Oficios de Murcia y en sus incursiones o montajes teatrales, todo ello en sus primeros años formativos; pero destilado, fundamentalmente, bajo la luz de una aspiración vital y humana: la arquitectura entendida como un humilde homenaje a las pisadas anónimas del habitar de la ciudad y a las huellas acaecidas sobre el paisaje. Quizás ahí quiebra de modo holístico todo su trabajo, al entender que la arquitectura no es únicamente el escenario específico, interdisciplinar, del proyecto, el diseño o la construcción de la ciudad, sino, ante todo, el lugar del habitar social.

\section{Agradecimientos}

Los autores expresan su afectuoso agradecimiento al arquitecto Juan Antonio Molina por su continua disponibilidad, ayuda y atención. Especialmente significativa ha sido la colaboración de Candelaria Andrea López que se ha convertido en valiosa e imprescindible compañera de viaje en este y otros trabajos de investigación. Asimismo, se expresa la gratitud a Clemen Corbalán y a los profesores Roberto Londoño -por sus interesantes apuntes iniciales y orientaciones-, así como a Rodrigo Martin Iglesias y Marcelo Robles; todos compañeros docentes, y estimulantes catalizadores de conocimiento. Por último, se desea manifestar que el presente artículo se ha desarrollado como parte de un proyecto I+D+I titulado «La representación del tiempo en la expresión gráfica», con referencia proyecto emergente GRE18-10 financiado, en pública concurrencia, por el Vicerrectorado de Investigación y Transferencia de Conocimiento de la Universidad de Alicante.

\section{Autoría}

El trabajo se ha desarrollado por ambos autores. Desde las primeras pesquisas de archivo, pasando por la conceptualización y diseño de la investigación, hasta el intercambio de la construcción literaria y formal de la misma.

Conflicto de intereses: Los autores declaran que no hay conflicto de intereses. 


\section{Bibliografía}

Augé, M. (2004). Los no lugares. Espacios del anonimato. Una antropología de la sobremodernidad. Barcelona, España: Gedisa. Recuperado de https://designblog.uniandes.edu.co/blogs/dise2609/files/ 2009/03/marc-auge-los-no-lugares.pdf

Baudrillard, J. y Nouvel, J. (2000). Los objetos singulares. Arquitectura y filosofía. Buenos Aires, Argentina: Fondo de Cultura Económica. Recuperado de https://arqlat.files.wordpress.com/2017/08/ baudrillard-nouvel-objetos-singulares-2000.pdf

Boeri, S. (2011). L’anti Città. Bari, Italia: Laterzza.

Bohigas, O. (1968). Una posible 'Escuela de Barcelona'. Revista de Arquitectura, 118, 24-30. Recuperado de https://www.coam.org/media/Default\%20Files/fundacion/biblioteca/revista-arquitectura100/1959-1973/docs/revista-articulos/revista-arquitectura-1968-n118-pag24-30.pdf

Bohigas, O. (2004). Contra la incontinencia urbana. Análisis moral de la arquitectura y el urbanismo. Barcelona, España: Electa.

Bresciani L.,L.E. (2020). Contra el conformismo. ARQ, 100, 152-153. DOI: http://dx.doi.org/10.4067/S0717-69962018000300152

Capitel, A. (1998). Arquitectura española del siglo XX. Madrid, España: Suma Artis.

Capitel, A. (2002). Dejando atrás el siglo moderno. La arquitectura española de las instituciones, 19932001. Revista Documentos de Arquitectura, 50, 3-24. Recuperado de http://oa.upm.es/44993/1/dejan do atras opt.pdf

Capitel, A. (2005). La arquitectura del patio. Barcelona, España: Gustavo Gili. Recuperado de http://oa.upm.es/35270/1/La arquitectura del patio.pdf

Cortés Pedrosa, J. (2018). La construcción del territorio mediterráneo desde una perspectiva ecológica. Observatorio Medioambiental, 21, 137-158. DOI: https://doi.org/10.5209/OBMD.62656

De Certeau, M. (1999). La invención de lo cotidiano. Ciudad de México, México: Universidad Iberoamericana.

De Las Rivas, J. (1992). El espacio como lugar, sobre la naturaleza de la forma urbana. Valladolid, España: Universidad de Valladolid.

Fernández Cox, C. (2000). El olvido del habitante. Summa +, 33, 26-29. Recuperado de http://revistasummamas.com.ar/revista pdf/33/26\#visor

Gehl, J. (2006). La humanización del espacio urbano. Madrid, España: Reverte.

Hervás Avilés, J. M. (1982). Cincuenta años de arquitectura en Murcia. La arquitectura, los arquitectos y su organización colegial. 1931/1982. Murcia, España: COAMU.

Levinson, J. (2020). The daring diagonal. Recuperado de http://joellevinson.info/the-daring-diagonal/

Lynch, K. (2008). La imagen de la ciudad. Barcelona, España: Gustavo Gili. Recuperado de https://www.academia.edu/7869348/Kevin Lynch La Imagen de la Ciudad

ACE, 16 (4.6) CC BY-ND 3.0 ES | UPC Barcelona, España | Construir en el lugar. Juan Antonio Molina Serrano: 22

hacia el paisaje, la ciudad y el habitar. DOI: http://dx.doi.org/10.5821/ace.16.46.9756 
Martí Arís, C. (2008). Pabellón y patio, elementos de la arquitectura moderna. Dearquitectura, 02, 7 27. Recuperado de https://www.redalyc.org/articulo.oa?id=341630311002

Moneo, R. (1995). Contra la indiferencia como norma. Santiago de Chile, Chile: Ediciones ARQ.

Montaner, J. M. (1994). Ensayo sobre arquitectura moderna y lugar. La Coruña, España: Boletín Académico.

Montaner, J. M. (2002). Posiciones en la arquitectura española. 1993-2002. Revista Documentos de Arquitectura, 50, 25-48.

Montaner, J. M. (2008). Sistemas arquitectónicos contemporáneos. Barcelona, España: Gustavo Gili.

Montaner, J. M. (2014). Del diagrama a las experiencias, hacia una arquitectura de la acción. Barcelona, España: Gustavo Gili.

Montaner, J. M. (2015). La arquitectura de la vivienda colectiva. Políticas y proyectos en la ciudad contemporánea. Madrid, España: Reverte.

Moreno Ortolano, J. (2017). Juan Antonio Molina Serrano: una modernidad contextual. Vivienda \& Ciudad, 4, 109-120.

Moreno Ortolano, J. (2018). Desafíos y alternativas en la intervención en el patrimonio construido. Apuntes sobre las actuaciones de Juan Antonio Molina Serrano. Área, 24, 179-195. Recuperado de https://area.fadu.uba.ar/wp-content/uploads/AREA24/AREA24 Moreno Ortolano.pdf

Moreno Ortolano, J. (2021). Juan Antonio Molina Serrano. Traspasar, caminar, detenerse. Bogotá, Colombia: Las Escalas de lo Humano. Colección: Construcción de lo Público. Universidad de los Andes y Universidad Nacional de Colombia. (En prensa).

Muñoz, M. T. (1982). A los cincuenta años del Estilo Internacional. Arquitectura, 237, 55-64. Recuperado de http://oa.upm.es/39761/1/1982 estilo opt.pdf

Norberg-Schulz, C. (1975). Existencia, espacio y arquitectura. Barcelona, España: Blume. Recuperado de https://www.academia.edu/10939143/Existencia espacio y arquitectura Norberg Schultz

Norberg-Schulz, C. (1979). Genius Loci. Paesaggio, Ambiente, Architettura. Milán, Italia: Electa. DOI: 10.12795/ppa.2020.i23.13

Pallasmaa, J. (2016). Habitar. Barcelona, España: Gustavo Gili.

Thornberg, J.M. (1973). La arquitectura como lugar. Barcelona, Gustavo Gili.

Thornberg, J.M. (2011). El diálogo entre proyecto y lugar. Un reto para la arquitectura del siglo XXI. Cuadernos de Proyectos Arquitectónicos, 2, 33-38. Recuperado de http://polired.upm.es/index.php/proyectos arquitectonicos/article/view/1411/1418

VV.AA. (2020). ARQ, 46, 4-7. Recuperado de https://issuu.com/edicionesarq/docs/arq 46

VV.AA. (2019). Escenarios. Juan Antonio Molina Serrano. Murcia, España: DGBC-CCT-RM, COARM, Dpto. Arquitectura UPCtg.

ACE, 16 (4.6) CC BY-ND 3.0 ES | UPC Barcelona, España | Construir en el lugar. Juan Antonio Molina Serrano:

hacia el paisaje, la ciudad y el habitar. DOI: http://dx.doi.org/10.5821/ace.16.46.9756 